Research Article

\title{
Examination of Structures Built with Tunnel Formwork in Terms of Strength and Cost according to the Earthquake Regulations of 2007 and 2018
}

\author{
Yilmaz Dilek (D) and Abdulhalim Karasin \\ Dicle University, Faculty of Engineering, Department of Civil Engineering, Diyarbakir 21000, Turkey \\ Correspondence should be addressed to Yilmaz Dilek; dryilmazdilek@gmail.com
}

Received 2 July 2021; Accepted 18 November 2021; Published 10 December 2021

Academic Editor: Stefano Galassi

Copyright (C) 2021 Yilmaz Dilek and Abdulhalim Karasin. This is an open access article distributed under the Creative Commons Attribution License, which permits unrestricted use, distribution, and reproduction in any medium, provided the original work is properly cited.

\begin{abstract}
Turkey has always been exposed to active fault lines passing through and unpredictable seismic activities. These ground movements have always been one of the important issues in our country, which have led to great destruction and loss of lives and property in its past. For this reason, our earthquake regulations, which aim to design more accurately against earthquake movements, are continuously made improvements. In this study, the analysis of structures built with tunnel formwork system which is popular today with the new earthquake regulations entered into force in 2018, and the strength and cost according to the old earthquake regulation in terms of what differences will occur. In addition to the study, we investigated how the number of floors and regular floor plans affects the results. For this purpose, two types of structures were covered with 5, 10, and 15 storey models created, first in the 2007 earthquake regulation; then, in the 2018 earthquake regulation, design analysis was carried out. As a result, the new earthquake regulation, which came into force in 2018 , led to more realistic results as it provides more accurate environmental inputs used in design analysis. Earthquake loads affecting floors increased by $3.9 \%$ for 5 storey in regular structures, decreasing by $38.4 \%$ for 10 stories and $43.3 \%$ for 15 stories. More irregular structures increased $7.3 \%$ for 5 storey, 10 -storey structures decreased by $38.9 \%$, and 15 -storey structures decreased by $43.6 \%$. In terms of cost, there was a $0.07 \%$ increase in total cost in 5-storey buildings, $2.45 \%$ in 10 -storey buildings, and a $3.91 \%$ reduction in 15 -storey buildings. In addition to these results, an empirical formula that estimates $\mathrm{m}^{2}$ prices depending on the number of floors was obtained.
\end{abstract}

\section{Introduction}

Tunnel formwork systems are a type of formwork system to harden the concrete material in desired shapes similar to other formwork systems. This system can be expressed as a cast construction system where flooring and walls are cast as large formwork elements at one time. Tunnel formwork systems can enable low-cost, fast, and serial construction to meet the increasing housing demand after World War II is a molding system that first emerged in France [1]. The most important element that differentiates tunnel formwork systems is to have a fast and practical construction method. The main purpose is to practically dismount the formwork once it is constructed rather than dismounting and reassembling the formwork for each floor. A tunnel formwork has a 500-usage lifecycle. However, this depends on the formwork quality and used technology, low-level damage is possible due to usage, and formwork might need partial repair.

In terms of cost, two factors make the tunnel formwork method advantageous: the first one is the low labor and general expenses due to fast construction. The second advantage is that once the formwork is prepared, it can be used with high numbers. Iterative use of a tunnel formwork system in a project and building heights being extremely important factors in terms of cost are highlighted in numerous studies. Within this framework, the effects of several floors and concrete classes in multistorey building construction with tunnel formwork in Turkey were investigated in previous studies [2]. According to the data obtained from the study, the system loses its applicability after a certain 
height. The cost increase is higher than expected after the 42 nd floor, it was found that projects with entirely shear wall applied with this or similar tunnel formwork system was not a rational choice in economic terms for 42nd and following floors. In another study, a master's thesis that compared tunnel formwork systems in multistorey structures with conventional (traditional) systems in terms of time, dynamic analysis of a building with two different loadbearing systems was conducted, and strength, construction speed, and cost comparisons were conducted on commercial ideStatik software. The results of that study showed tunnel formwork systems had high first investment cost than conventional formwork systems. However, due to advantages such as a longer formwork lifecycle than the other formwork systems and being a couple of times faster in terms of time, tunnel formwork was highlighted as more advantageous for serial structure constructions (mass housing) [3].

There are few studies on strength analysis of tunnel formwork systems. For example, a study that experimentally investigated the earthquake behavior of these systems stated that shear wall systems were the most suitable and cheapest method to increase the multistorey reinforced concrete structures [4]. Another study on the effect of shear wall reinforced concrete elements that have a similar principle to tunnel formwork systems on the strength investigated the performances and capacities of shear walls of 2 different structures with the same architectural design but a different number of floors 2 -storey 5 -storey structures. The study results showed that too rigid structure caused the seismic forces to be intensely experienced by the building users, caused unnecessary cracks, and had high strength capacity [5]. In another study, behaviors of buildings constructed with tunnel formwork under earthquake loads were investigated. Structures constructed with shear wall and tunnel formwork were comparatively considered by considering the earthquake areas and surface parameters in TSC-2007. The 22-storey building in that study had 2.5 times higher base shear strength than the 11storey building, and the displacement at the top floor increased 5 times. These displacements were reported to be higher on the side with less rigidity [6].

This study is divided into two sections. The first section investigated the structures constructed with tunnel formwork systems in terms of strength. For that reason, statistical analysis of 2 different building types with 5, 10, and 15-storey with 2 different architectural floor plans was applied with commercial software both for the 2007 Earthquake Regulation and 2018 Earthquake Regulation [7]. The effects of tunnel formwork system buildings with different structures were comparatively revealed for 2007 earthquake regulations [8] and new 2018 earthquake regulations [9] in plan type strength. The second section investigates the effects of several floors and floor plans in terms of cost for buildings constructed with these systems.

\section{Materials and Methods}

2.1. Method. In this study, the effects of tunnel formwork system buildings with different structures were comparatively revealed for 2007 earthquake regulations and new 2018 earthquake regulations regarding the number of floors, plan type strength, and cost. To make a comparative analysis, commercial software that enables analysis for both earthquake regulations is needed. The comparative analysis was made by using commercial software that provided these properties. Under the scope of the thesis study, statistical analysis of 2 different building types with 5, 10, and 15-storey with 6 different architectural floor plans were applied with commercial software both for the 2007 Earthquake Regulation and 2018 Earthquake Regulation. For the first stage, a total of $2 \times 3 \times 2=12$ static analysis was provided.

Still, the different number of floors with the same parameters and $12+2=14$ analysis were conducted here. Static analysis was conducted with a local commercial software called ideCAD for ease of use, clarity, being accepted by the reports in our country, used in certain academic studies, and the company supporting this study by giving a free license. Then, to check the existing solutions, analysis was repeated with another commercial software for buildings with the same plan.

The reports for the analysis were explained in detail to show the separate load values of each element, and summary tables were created for interpreting the data.

A detailed approximate cost was calculated using the program's quantities data and the analysis and unit prices by the Ministry of Environment and Urban Affairs 2019. However, since the environmental and urban affairs analysis did not provide realistic results for tunnel formwork constructions, the analysis was conducted by collecting data from mutual interviews with various tunnel formwork subcontractor firms in the market. As a result, minimum required conditions were met to make a healthy comparison for the sample projects.

2.2. Structures in This Study. For this study, shear wall structures with two different architectural designs were selected from structures planned to be built under an official contract job opened by TOKI on the EKAP contract job system: BK and CK blocks (Figures 1 and 2).

If the characteristic properties of both plans were considered, there were 4 flats in both plans, and the BK block floor area was $580 \mathrm{~m}^{2}$ and the CK block floor area was $730 \mathrm{~m}^{2}$. Additionally, while the BK block was almost completely symmetrical, the CK block had a visible difference between $X$ and $Y$ lengths. This difference will guide to measuring the impact of the structural plan on strength and cost.

2.3. Earthquake Regulations in Turkey. The first earthquake regulation in Turkey entered into force after the 1939 Erzincan earthquake. This regulation entered into force in 1940. The Italian earthquake regulation was considered the template, and naturally, the structure's location was not important for the analysis conducted in those days. To prevent this, earthquake area maps were prepared in 1942, and the areas of the structure finally became important and included in the calculations [10]. 


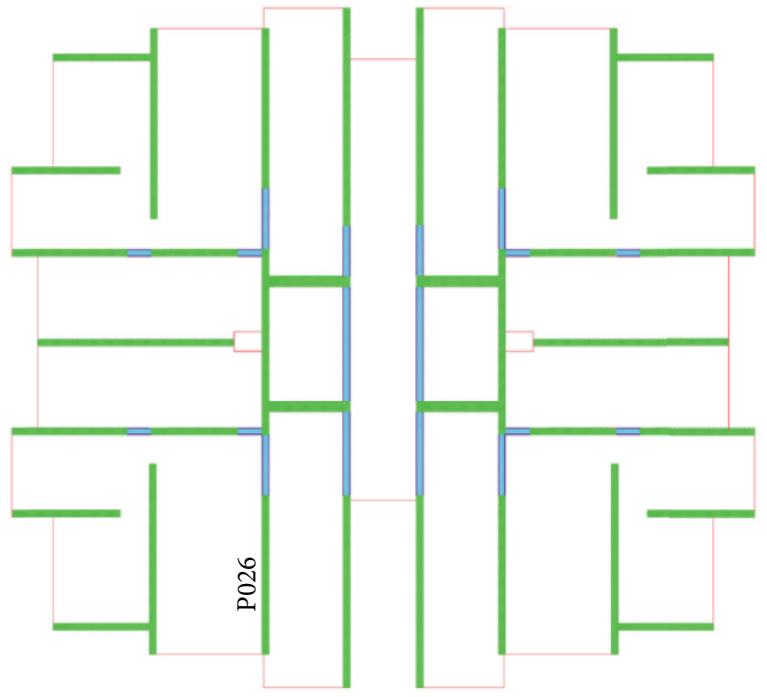

Figure 1: BK-type floor plan. $X=29 \mathrm{~m}, Y=26.5 \mathrm{~m} .4$ symmetrical flats. Plan area $580 \mathrm{~m}^{2}$.

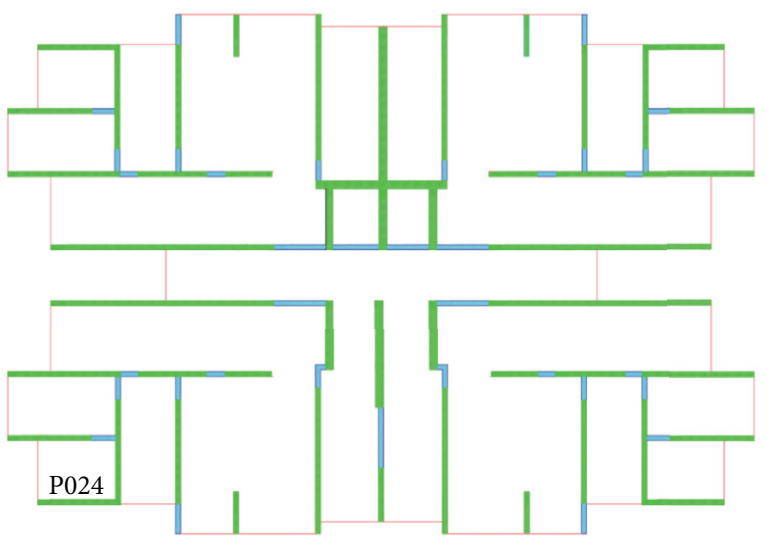

FIGURe 2: CK-type floor plan. $X=37.40 \mathrm{~m}, Y=26 \mathrm{~m} .4$ symmetrical flats. Plan area $730 \mathrm{~m}^{2}$.

With earthquake regulations published in 1968, the advanced calculation methods that are used today have become usable. The limitations for the minimum dimensions of reinforced concrete elements were first expressed in this regulation. The term continuity was first introduced in the earthquake regulation published in 1975 . This regulation provided recommendations related to reinforced concrete component connections, twist regions, reinforcement details for tensile behavior, and component dimensions. The earthquake regulation that entered into force in 1997 made rules related to ductile design mandatory for buildings. [10].

There are no significant differences between the 1997 earthquake regulation and the 2007 earthquake regulation. Most of the design rules and calculations in the 2007 earthquake regulation were already used in the earthquake regulation published in 1997. In general, more details were added to calculations in certain areas (such as steel) specifically. The sections about wood and mudbrick buildings were not included in the 2007 earthquake regulation. In addition to that, new sections were added for the existing buildings. [11] All earthquake codes that have been put into effect so far can be seen in Table 1.

When Earthquake Regulation in Turkey (2007) and Building Earthquake Regulation in Turkey (2018) are compared, it is possible to find numerous differences. Roughly, TSCB-2018 had more comprehensive and large content than TSC-2007. While TSCB-2018 content was 395 pages (416 pages with the content page), and TSC2007 content was 156 pages. In terms of content, while TSC-2007 identified calculation and design rules only for reinforced concrete, steel, and masonry structures, TSCB2018 added cast-in-place reinforced concrete building, precast reinforced concrete buildings, steel, light-steel buildings, masonry buildings, wood buildings, high-rise buildings, insulated buildings, and existing buildings. In TSC-2007 (Figure 3), while the ground acceleration of the locations within the borders of Turkey was included, the calculations were made according to 5 identified earthquake areas. These levels were removed in TSCB-2018 (Figure 4) regulation, maps obtained from long years of research were combined, and 16 more sensitive maps were obtained.

Since the TSC-2007 regulation, the design was conducted only on one level. A new parameter called Earthquake Ground Movement Levels (DD) was added to TSCB-2018. This level of regulation made designs for intense earthquakes with a $10 \%$ probability of exceedance in 50 years and a repetition period of 475 years.

With the new regulation, 4 earthquake ground movement levels were defined as follows:

(i) DD-1: extremely rare earthquake but the largest possible earthquake with $2 \%$ of probability of exceedance in 50 years and a repetition period of 2475 years

(ii) DD-2: rare earthquake with $10 \%$ of probability of exceedance in 50 years and a repetition period of 475 years

(iii) DD-3: highly frequent earthquake with $50 \%$ of probability of exceedance in 50 years and a repetition period of 72 years

(iv) DD-4: rare earthquake with $68 \%$ of probability of exceedance in 50 years and a repetition period of 43 years

For calculations, DD-2 was predicted to be standard. This level was the same as the level applied in 2007. While buildings in the high class and special qualities used DD-1, buildings without any qualities or properties that will not bring loss of life or property might use DD-3 and DD-4 options.

In the TSC-2007 regulation, a coefficient of importance was designed for buildings. This coefficient is directly included in earthquake force calculation with verbal expression stating that the user density and number of users in the building are important. 4 types of importance levels were defined with TSC-2007, and the design followed these levels; 
TABLE 1: Regulations entered into force in Turkey.

\begin{tabular}{lc}
\hline Regulation name & Effective date \\
\hline Italian structure regulations for constructions in earthquake regions & 1940 \\
Interim structure regulations in earthquake regions & 1944 \\
Structure regulations for earthquake regions in Turkey & 1949 \\
Regulation about structures to be constructed in earthquake areas & 1953 \\
Regulation about structures to be constructed in disaster areas & 1962 \\
Regulation about structures to be constructed in disaster areas & 1968 \\
Regulation about structures to be constructed in disaster areas & 1975 \\
Regulation about structures to be constructed in disaster areas & 1998 \\
Regulation about buildings to be constructed in earthquake areas & 2007 \\
Building earthquake regulation in Turkey & 2018 \\
\hline
\end{tabular}

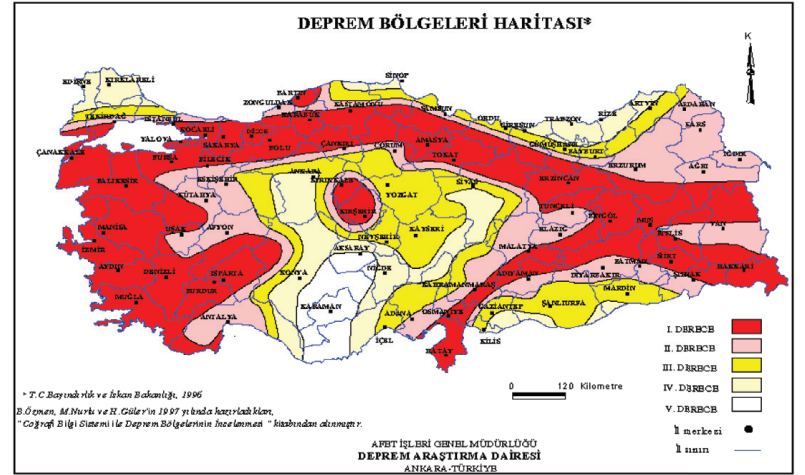

FIGURE 3: Earthquake map used in TSC-2007 earthquake regulation [12].

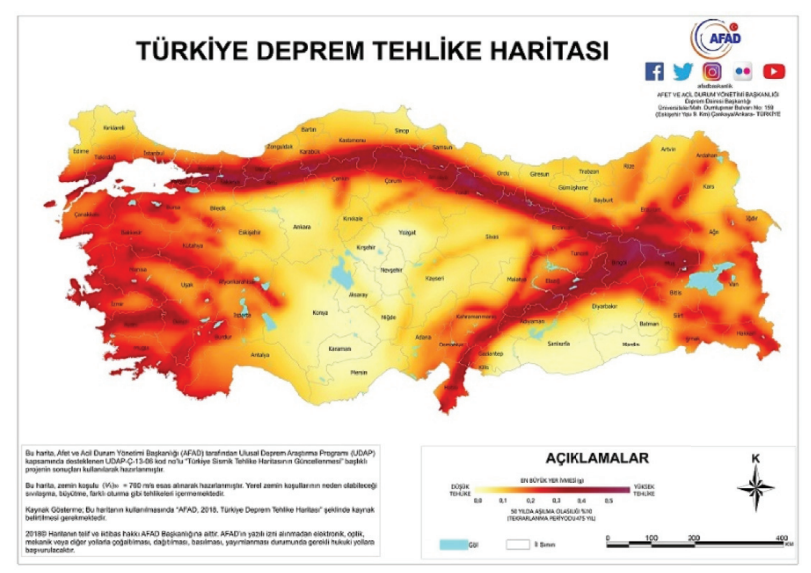

Figure 4: New earthquake map used in TSCB-2018 earthquake regulation [13].

however, with TSCB-2018, 3 types of levels were defined, and the definitions were changed.

TSC-2007 had 4 ground groups and 4 types of local ground classes connected to these groups. The Ground Group table was eliminated with TSCB-2018, and instead, a single table that directly shows ground classes was introduced. According to this table, there are 6 types of ground classes, and these classes are distributed from hard rock (ZA) to ground that requires special survey and assessment for the field $(\mathrm{ZF})$ as $\mathrm{ZA}, \mathrm{ZB}, \mathrm{ZC}, \mathrm{ZD} \mathrm{ZE}$, and $\mathrm{ZF}$. For ZE class ground, project planning by expert engineers with authorization documents became mandatory. Additionally, project planning by experts with authorization documents became mandatory for calculation methods with nonlinear time definition area, high-rise class building design, insulated building design, and structure-pile-ground interactive foundation models.

2.4. Analysis. Two different structural analysis programs were used in the analysis. The first one was SAP 2000 program by Computers and Structures company and the second one was ideCAD program by ideYAPI company. For the analysis, ideCAD Statik IDS v.10.05 version and v10 TIME 0094 student lock defined for me was used. The first question on the analysis setting window of the program was which earthquake regulation will be selected to create the analysis model. With this option, separate analyses for both the 2007 earthquake regulation and 2018 earthquake regulation were reported for the projects (Figure 5).

2.5. Modelling. The correct modeling is important to correctly analyze the structures in this study. The trials showed that mistakes at shear-beam-transverse beam connections caused unrealistic values for the structure periods of the small-angle objects. The error check for the modeling can be conducted with the "Geometry Control" tool inside the program. If the control result does not show modeling-related problems, it can be said that there are no modeling errors. After creating the building models on the program, geometry controls were completed, and the analysis was conducted without any model error. As a material, C30 concrete and S420C reinforcement were used.

\section{Study Results and Discussion}

BK and CK-type structures were modeled in 5, 10, 15-storey forms, and analyses were applied for both old earthquake regulation and new earthquake regulation in line with the analysis conditions. The obtained reports were evaluated in terms of strength and cost.

\subsection{Comparisons of Models and Regulations}

3.1.1. Period Comparison. The periods and comparisons for the analysis are given in Table 2. 


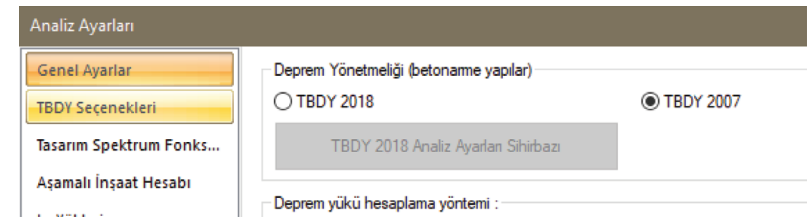

Figure 5: Analysis settings earthquake regulation selection dialogue.

TABle 2: Periods for structures.

\begin{tabular}{lccccccc}
\hline Structure & Mode & \multicolumn{3}{c}{ BK period $(\mathrm{s})$} & \multicolumn{3}{c}{ CK period (s) } \\
& & TSC-2007 & TSCB-2018 & Difference (\%) & TSC-2007 & TSCB-2018 & Difference (\%) \\
\hline 5 & 1 & 0.42 & 0.44 & 7.3 & 0.41 & 0.43 & 4.8 \\
10 & 1 & 0.71 & 0.76 & 7.0 & 0.77 & 0.81 & 1.41 \\
15 & 1 & 1.16 & 1.23 & 6.1 & 1.38 & 2.2 \\
\hline
\end{tabular}

When Table 2 is examined, it can be seen that there is an increase in the natural vibration period values of the structure in buildings designed according to the 2018 regulation compared to the buildings designed according to the 2007 regulation. Here, the biggest impact on the period values of the building is that it has become obligatory to consider the cross section stiffnesses in the building designs according to the calculation principles in the 2018 regulation.

Since the 2018 Earthquake regulation had new definitions for an interactive map, ground motion, and surface motion, the same studies were included in the analysis. The results show an increase in structure periods for new earthquake regulation. The main reason is the more sensitive interactive earthquake map and more realistic application of the calculated earthquake loads on the floors. These changing parameters impact the structure's natural period results.

If TSCB-2018 and TSC-2007 TDY are compared, some calculation additions are visible in the new earthquake regulation.

"Identification of Dominant Natural Vibration Period of the Building" in TSCB-2018 article 4.7.3 is calculated with the following equation.

$$
T_{p}^{(x)}=2 \pi\left(\frac{\sum_{i=1}^{N} m_{i} d_{f i}^{(x) 2}}{\sum_{i=1}^{N} F_{f i}^{(x)} d_{f i}^{(x)}}\right)^{1 / 2} .
$$

Certain limitations were introduced with 2018 TBDY. When compared to TSC-2007, earthquake direction $(x)$ was shown with an operator as addition, and there was an additional condition of not taking the natural period higher than $0.1 \mathrm{~N}$ for building with several floors $N>13$ except the basement floor (s) independent of the values calculated with this equation. Thus, the structure is separately considered for the material, coefficient, shear wall, or framed structure, providing a more accurate result. The importance of building natural period is high and natural structure period is certainly investigation for a structural design. It is not desired for the natural vibration period of a structure and the surface to intersect. When the oscillation direction of the building and the oscillation direction of the ground are synchronous, a mostly destructive event called resonance occurs. When the structure and the ground intersect, the period can be changed with various strategies. For example, building form can be changed to decrease the structure's natural period. This is possible by decreasing the height, decreasing the slenderness ratio, and expanding the building base.

Another method is to increase the rigidity. Rigidity can be increased by using shear wall, increasing the number of shear walls, or strengthening the outer edges of the structure. Another method is to decrease the structural mass. The structure mass can be decreased by using lighter loadbearing systems and light nonbearing components (on walls, etc.). The structure form can be changed by increasing the height and slenderness ratio to increase the building's natural period. Decreasing rigidity is another method to increase the period. To do that, increasing rigid framed structure and frame opening and applying seismic insulation are among the periods to increase the structure period. Additionally, the sheer force obtained for shear walls might be lower on the lower floors than upper floors in some cases. The reason for that is decreased rigidity due to plastic joint formation on the lower level shear wall and decreased shear force on the shear wall with changes in force distribution on the floor [14].

3.1.2. Shear Force on the Floors. Shear forces were obtained by combining mode combinations of component-specific results and calculated by the program according to the calculations on TSCB-2018 ATTACHMENT 4B. For Modal Contribution Coefficient a Base Shear Force Modal Effect Mass in these calculations,

$$
\begin{aligned}
\Gamma_{n}^{(\mathrm{X})} & =\frac{\sum_{i=1}^{N} m_{i} \Phi_{i(\mathrm{X}) \mathrm{n}}}{\sum_{i=1}^{N}\left(m_{i} \Phi_{\mathrm{ixn}}^{2}+m_{i} \Phi_{\mathrm{iyn}}^{2}+m_{\mathrm{i} \theta} \Phi_{i \mathrm{On}}^{2}\right)}, \\
m_{\mathrm{txn}}^{(\mathrm{X})} & =\Gamma_{n}^{(\mathrm{X})} \sum_{i=1}^{N} m_{i} \Phi_{\mathrm{ixn}}
\end{aligned}
$$


formulas are used. Here, for $(x)$ earthquake direction, nth vibration mode modal contribution coefficient is represented by $\Gamma_{\mathrm{n}}^{(\mathrm{X})}$ and the base shear force modal effective mass on the building $x$-axis is represented as $m_{\mathrm{txn}}^{(\mathrm{X})}$. Similarly, on load-bearing system $x$-axis direction, when the largest modal base shear force is represented by $V_{t x n, \max }^{(X)}$ and the corresponding largest base overturning moment is represented as $M_{\text {oxn,max }}^{(X)}$

$$
\begin{aligned}
V_{\mathrm{txn}, \max }^{(X)} & =\sum_{i=1}^{N} f_{i x n, \max }^{(X)}=m_{t x n}^{(X)} S_{a R}\left(T_{n}\right), \\
M_{\mathrm{oxn}, \max }^{(X)} & =\sum_{i=1}^{N} f_{i \mathrm{xn}, \max }^{(X)} H_{i} .
\end{aligned}
$$

Accordingly, the following results were obtained, and $X$ and $Y$ direction earthquake loads on the floors for $\mathrm{BK}$ (Table 3) and CK (Table 4) type structures are as follows:

When the results were investigated, while 5-storey structures provided more linear results, S-form distribution was visible for 10- and 15-storey structures. The reason for that is the periods of 5-storey structures corresponding to the ground period interval of TA: 0,090 , TB: 0,449 , and resonance occurred. The higher-rise structures clearly show that earthquake loads decreased with increased periods, and even in inverse resonance regions (the middle of S-shape), the force was dampened. As the middle region is closer to " 0 ," it is possible to say that this is the optimum solution. In addition, the higher the structure, the more prominent the $S$ form can be explained by the increase in the effect of higher modes. As it is known, the increase in the structure's height also means that the higher mode effects increase.

3.1.3. Floor Displacement. Another prominent point in the above tables is a linear relationship between the displacement and height of the frames. Floor displacements are given in Tables 5 and 6. Since the floor displacements are proportional to the floor shear load, any comments regarding the floor shear load can also be made for this section. In short, while there was a high level of displacement for 5storey structures for new earthquake regulation, lower displacement was obtained for 10- and 15-storey structures solved for TSC-2007. The main reason for that was the relationship between the building period and the ground period. Table 7 was constituted to see the floors' displacement regarding the floor below, that is, the relative floor displacement, more easily.

The relative storey displacement, $\Delta_{i}^{X}$, which expresses the displacement difference between two successive storeys under an $X$-direction earthquake effect for any column or shear wall in the building, is acquired as

$$
\Delta_{i}^{X}=u_{i}^{X}-u_{i-1}^{X} \text {. }
$$

$\Delta_{i}^{X}$ represents the horizontal displacements calculated according to the reduced seismic loads at the ends of any load-bearing element (column or shear wall) on consecutive floors of the building for the typical $(X)$ earthquake direction. As can be seen from the table, the displacements between successive floors are relatively less in the floors close to the ground and attic floors, while they are more prominent in the middle floors. This shows that the stress and oscillations caused by the lateral earthquake effect are more effective in the middle part of the building. Hence, the literal translation and displacement effects are maximum in the middle parts of the building.

It is the acceptance that the material and geometry changes in the building are not linear. When the displacement demand in the structure is reached for a certain earthquake effect, it is the control of whether the expected performance target from the building is achieved or not is the basic principle on which nonlinear calculation methods are based in determining the performance of structures under the influence of earthquakes [15]. Therefore, it was found appropriate to calculate the displacement values of the $\mathrm{BK}$ and $\mathrm{CK}$ structures obtained by the linear calculation method using the nonlinear calculation method, and Table 8 containing the comparative data was obtained.

Nonlinear pushover analyses calculated up to the roof displacement and linear analysis results were compared (Table 8 ). The results are similar. The point that draws attention here is that while similar results were obtained in both analyses in 2007 regulations in both BK and CK type structures, the floor displacement in the nonlinear analysis made according to the 2018 regulations is relatively higher than the linear analysis. This shows that nonlinear analysis handles the behaviour modeling of materials more realistically and more suitable for deformation, according to the 2018 regulation.

3.1.4. Effective Relative Floor Displacement. Relative floor displacement was separately calculated for both regulations and given below. While the control for 2007 earthquake regulation was $\delta_{\mathrm{i}}(\max ) / h \leq 0.02$, this was $\lambda \delta_{i}(\max ) /$ $h_{i}<=0,008$ for 2018 earthquake regulation.

Effective relative storey offsets are calculated separately for both regulations and given below. For typical $(X)$ earthquake direction, the effective relative storey $\mathrm{drift}, \delta_{i}^{x}$, for columns or shears, which are load-bearing elements at the $i$ th floor of the building, will be obtained as follows;

$$
\delta_{i}^{x}=\left(\frac{R}{I}\right) \Delta_{i}^{x}
$$

The amplification in this relation corresponds to the calculation of the "effective" relative storey drift based on the unreduced seismic loads due to the equal displacement rule.

Moreover, in the mode superposition method calculation in the 2007 earthquake regulation, it was stipulated that the sum of the effective masses calculated in each mode for the $x$ and $y$ directions should not be less than $90 \%$ of the total mass of the building. Still, this rate was increased to $95 \%$ in the 2018 regulation. In addition, it is stated that all modes that contribute at least $\% 3$ must be considered in the calculation steps.

As can be seen in the table prepared based on the behavior of the effective relative floor displacement in the $X$ direction of structure BK (Table 9) and CK (Table 10), the values of the relative floor displacement gradually increase with the increase of the building height when the structure 
TABLE 3: Floor shear force comparison of BK-type building for 2007 and 2018 regulations ( $x$-direction).

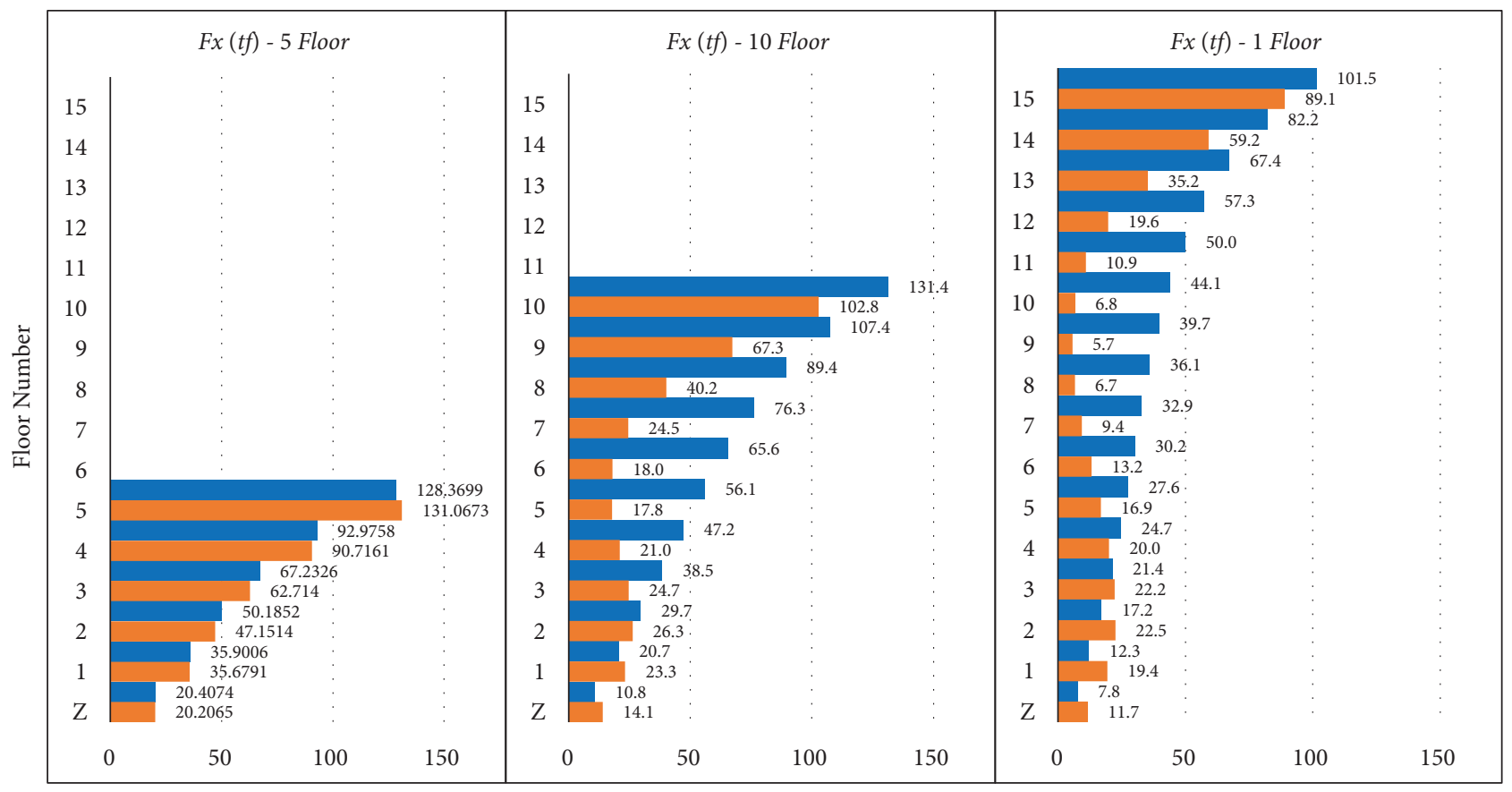

Shear Force (tf)

TSC-2007

TSCB-2018

TABLE 4: Floor shear force comparison of CK-type building for 2007 and 2018 regulations ( $x$-direction).

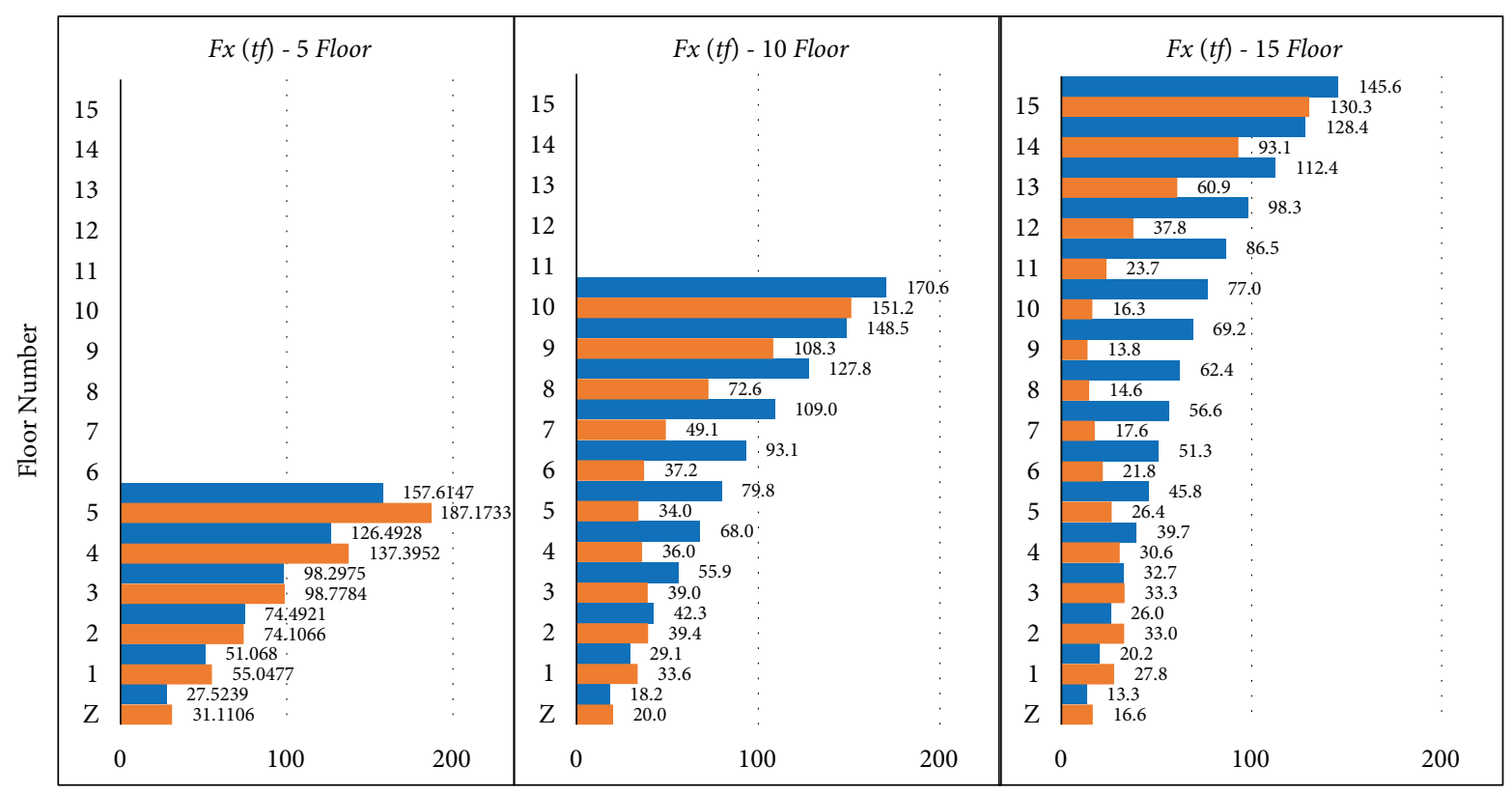

Shear Force (tf)

TSC-2007

$\square$ TSCB-2018 
TABLE 5: Comparison of floor displacement of BK-type building for 2007 and 2018 regulations ( $x$-direction).

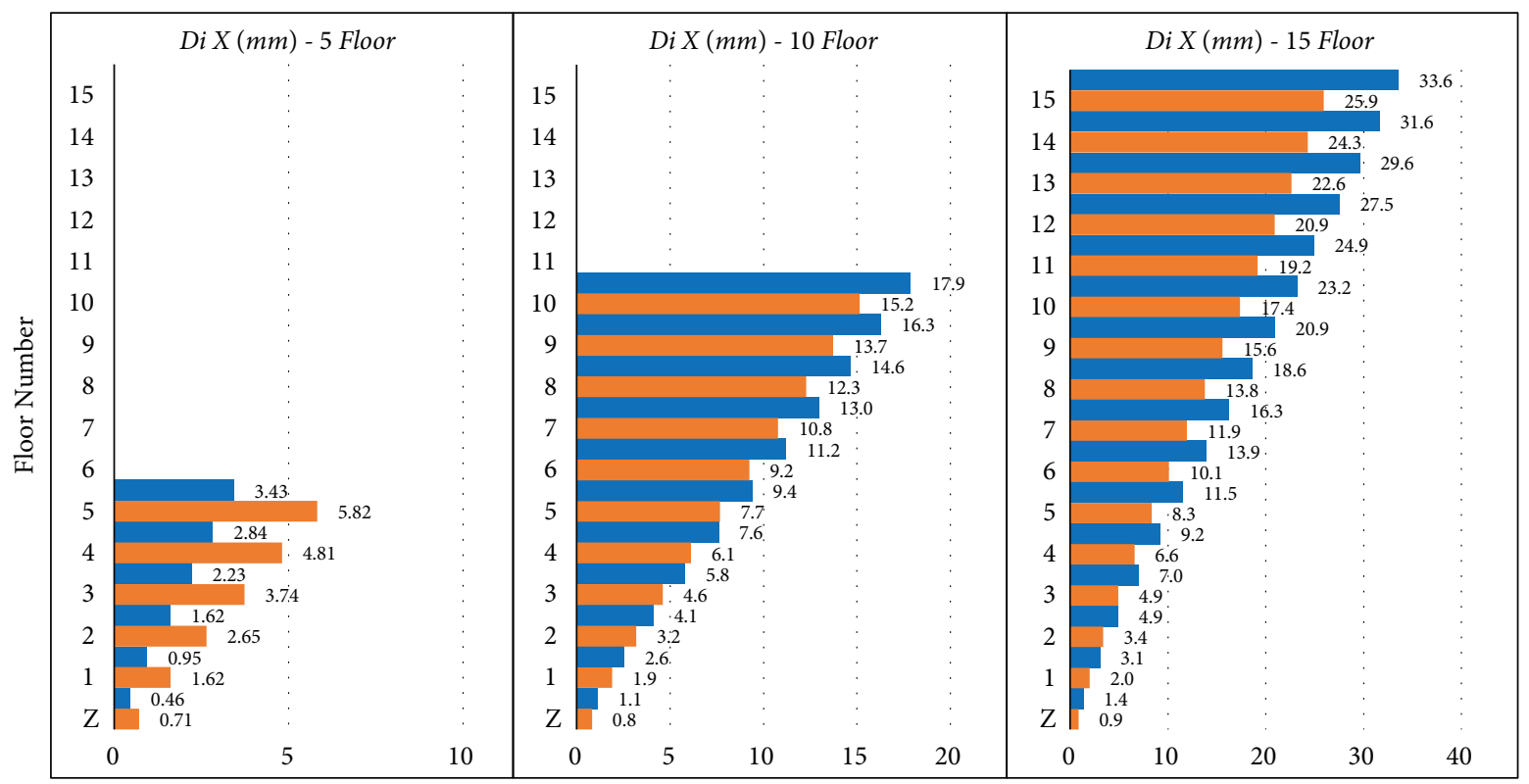

Floor Displacement (mm)

TSC-2007

TSCB-2018

TABle 6: Comparison of floor displacement of CK-type building for 2007 and 2018 regulations ( $x$-direction).

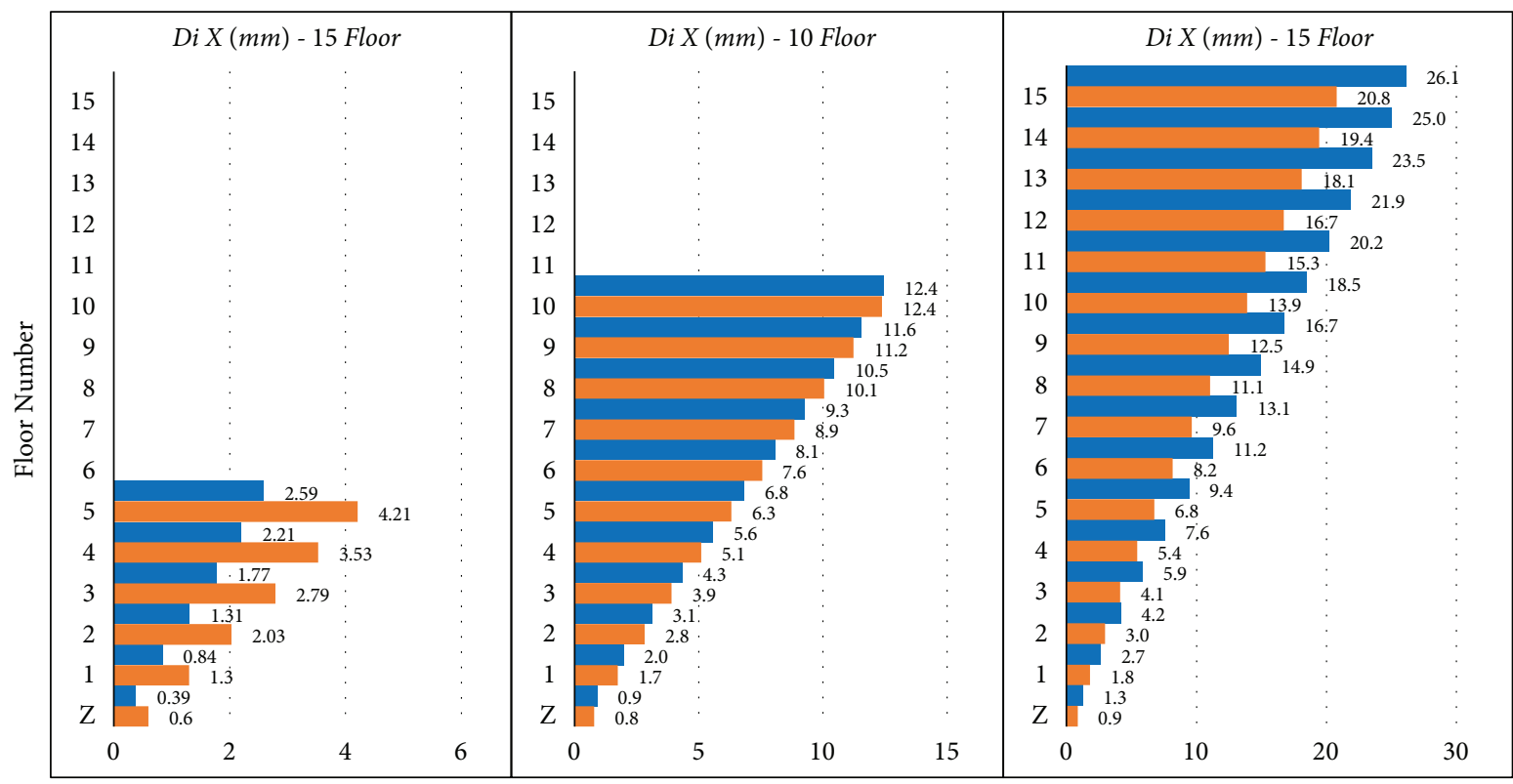

Floor Displacement (mm)

TSC-2007

TSCB-2018

was built according to the 2007 seismic regulations, and the structure tends to behave in the same way when it was built according to the 2018 TDBY regulations. The displacement between floors provided more stable results for the 2018 earthquake regulation, and it was seen that there was a concordance between neighboring floors. Moreover, it can be mentioned that the high mode effect increases as the height of the building increase in the accumulation of 
TABLE 7: Comparison of floor displacement of CK-type building for 2007 and 2018 regulations ( $x$-direction).

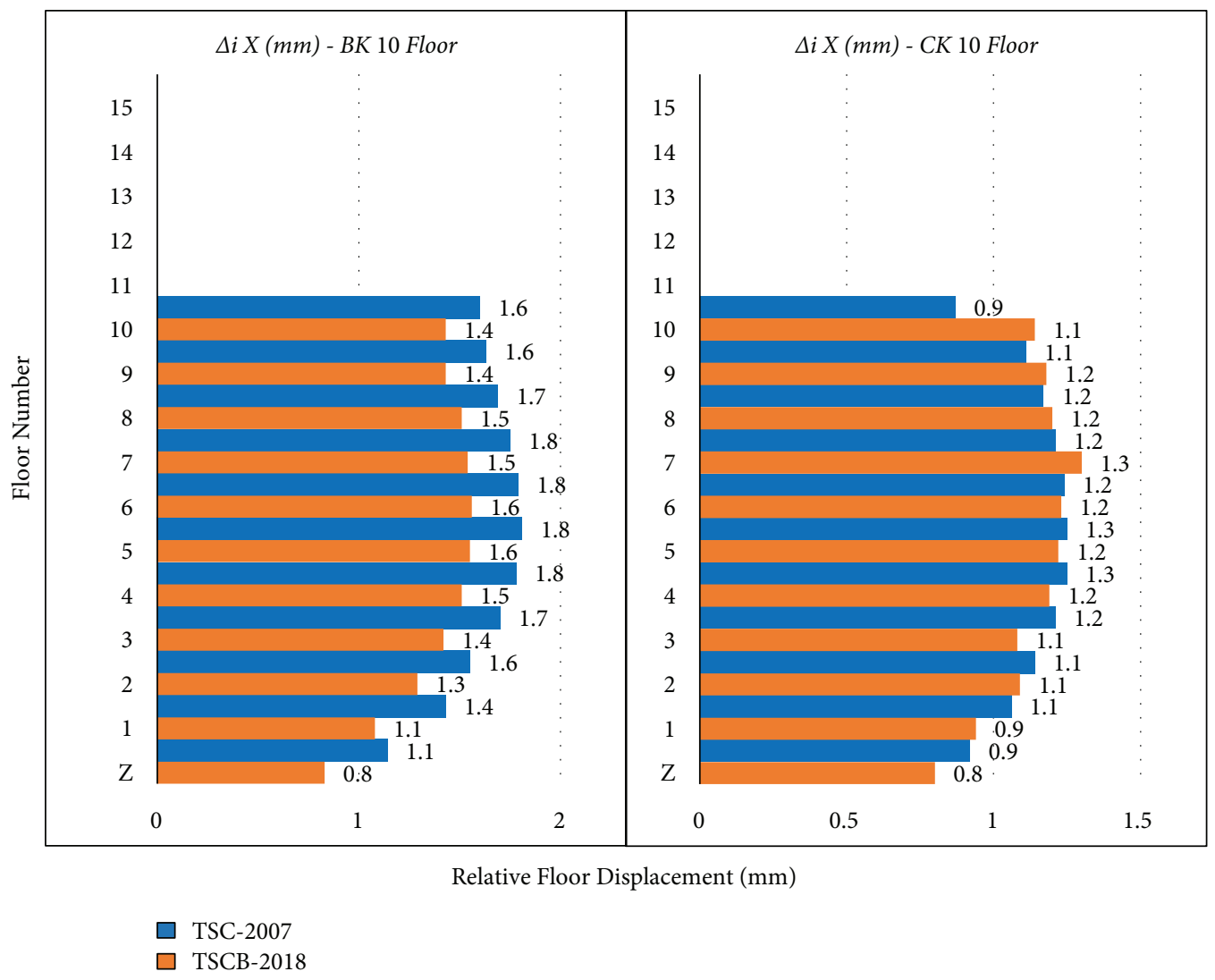

TABLE 8: Linear and nonlinear floor displacement comparison of a 10 storey BK and CK type building ( $x$-direction).

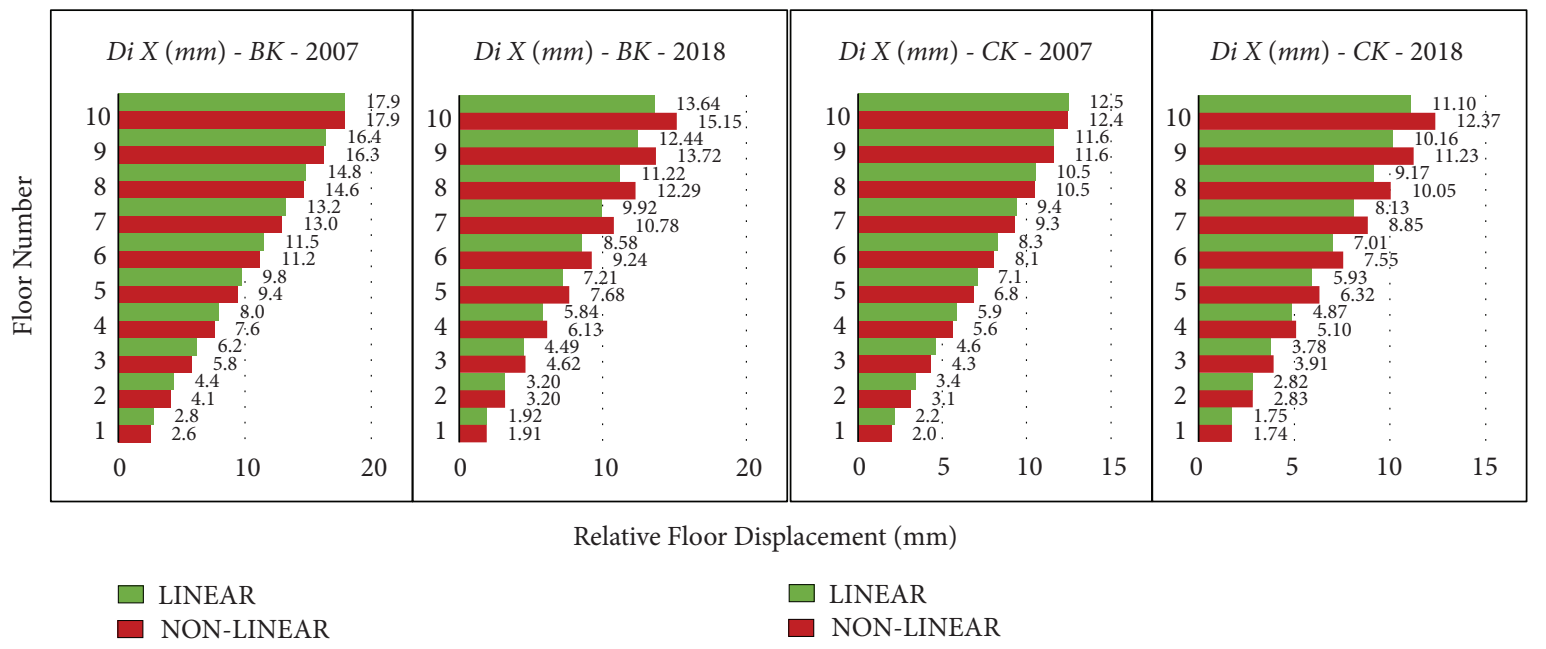

effective relative floor displacements. Since the natural vibration period of tall buildings is relatively larger in general, the effect of higher modes becomes more evident in dynamic analysis. Additionally, it is seen that one reason for this accumulation is the increase in mass participation in the calculations, which consists of the fact that the effective mass participation rate has been increased to 2018 in the \%95 earthquake code and that all modes with at least $\% 3$ effects must be calculated.

3.1.5. Reinforcement Changes. The study by Elci and Goker based on 2007 and 2018 earthquake regulations compared the earthquake performance of the reinforced concrete 
TABLE 9: Comparison of effective relative floor displacement of BK-type building for 2007 and 2018 regulations ( $x$-direction).

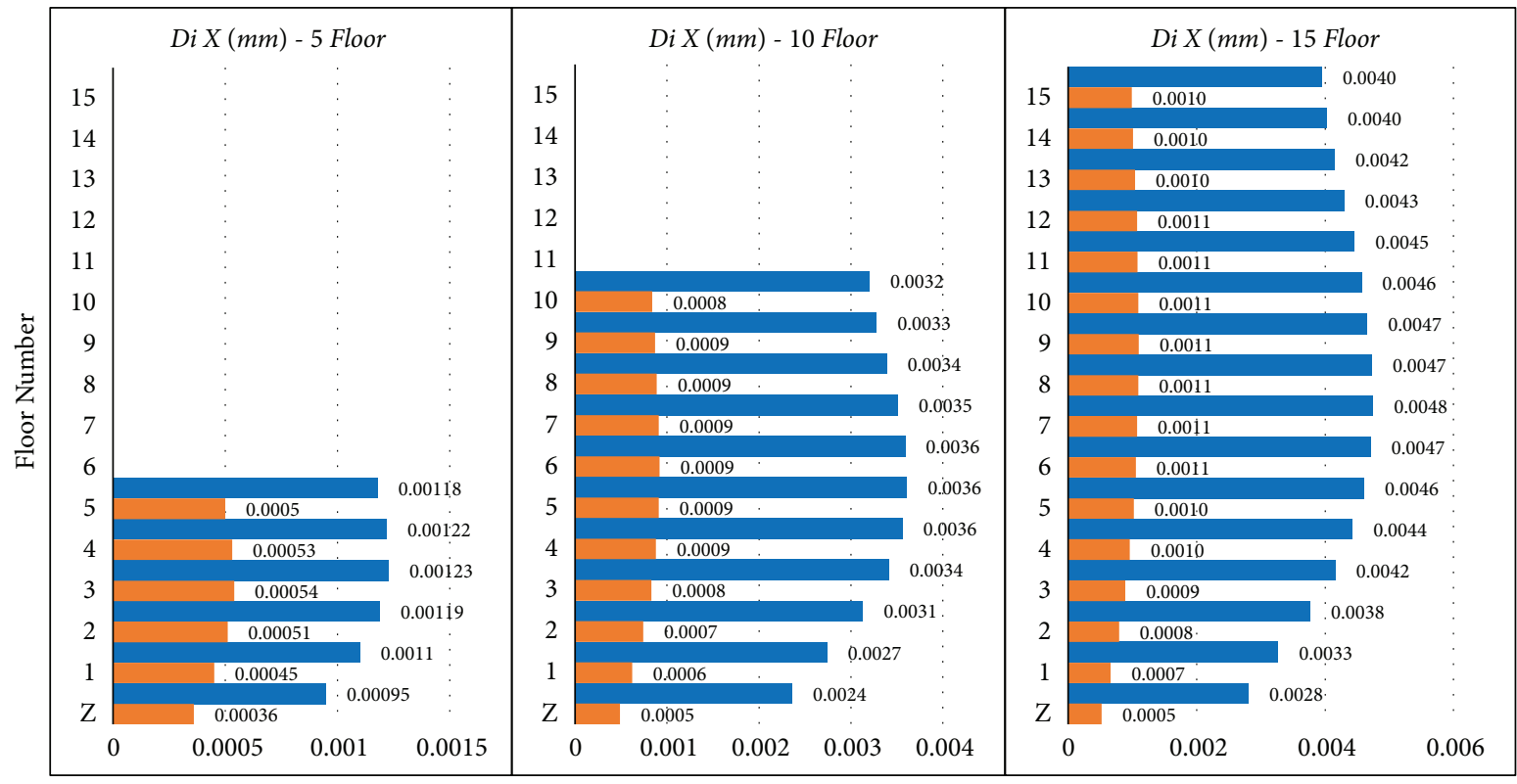

Effective Relative Floor Displacement ( $\mathrm{mm})$

TSC-2007

TSCB-2018

TABLE 10: Comparison of effective relative floor displacement of CK-type building for 2007 and 2018 regulations ( $x$-direction).

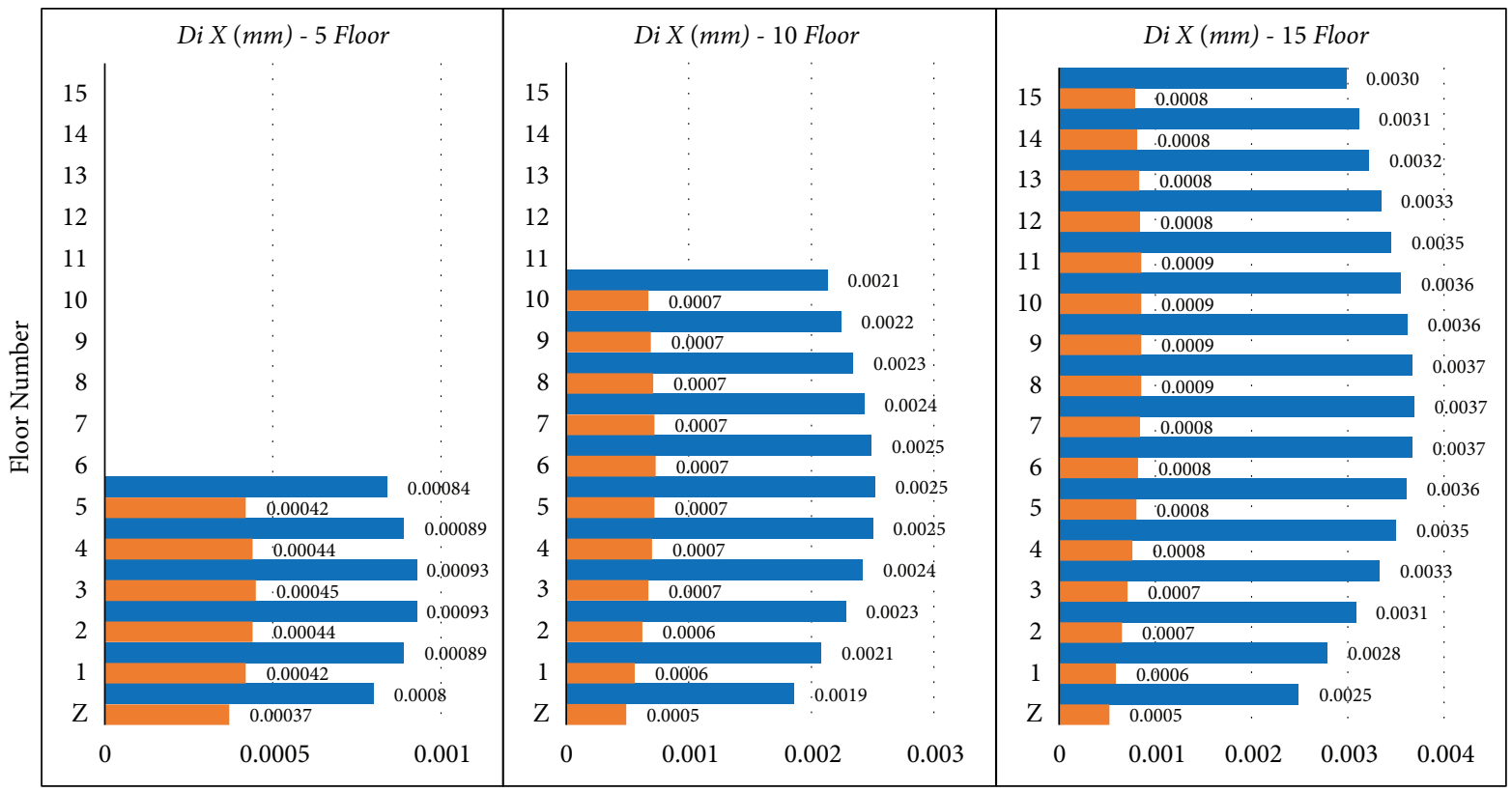

Effective Relative Floor Displacement (mm)

TSC-2007

TSCB-2018

columns and found that new regulations that entered into force in 2019 offered safer and more ductile solutions [16]. One random shear wall was selected for BK and CKtype, the reinforcements of these shear walls were analyzed in detail, and supportive results for that study were obtained.

When reinforcement placements of PZ026 (Figure 6) and PZ024 (Figure 7) shear walls were conducted for 
PZ026 (25/620) - BK 2007
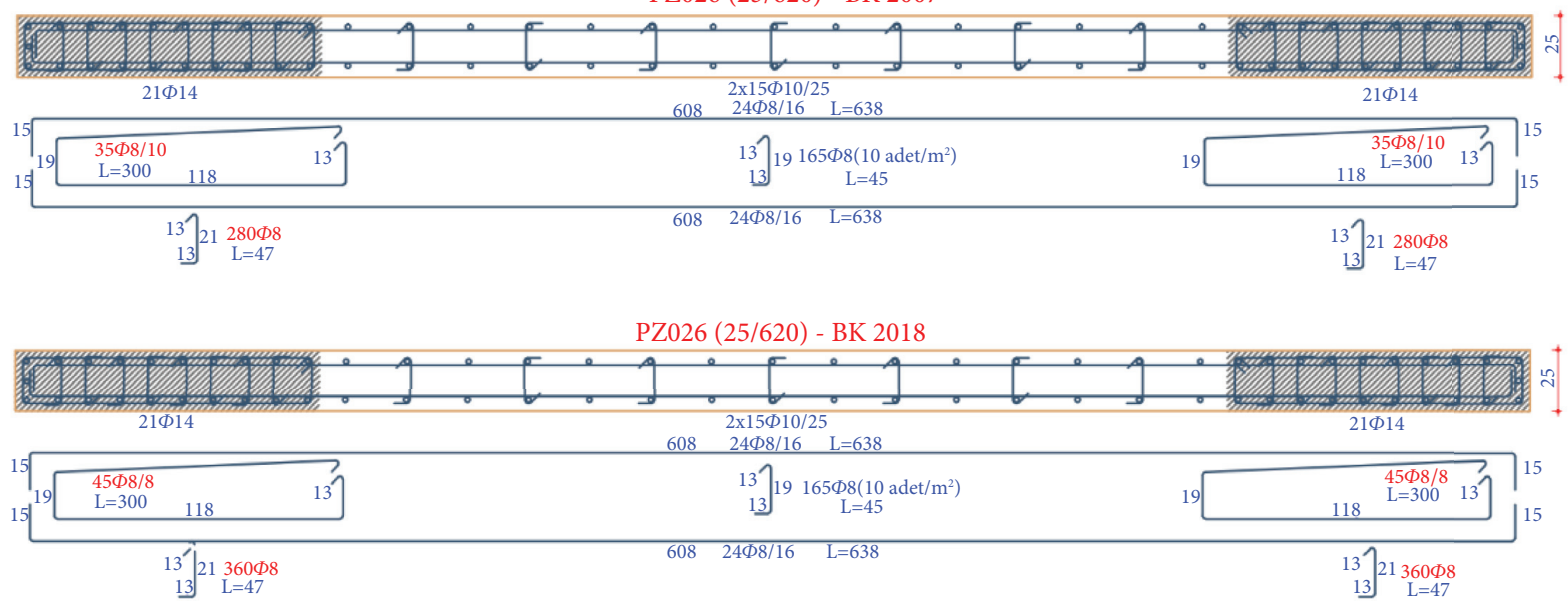

FIGURE 6: Randomly selected P026 shear wall ground floor reinforcement plan for 15-storey BK-type building.
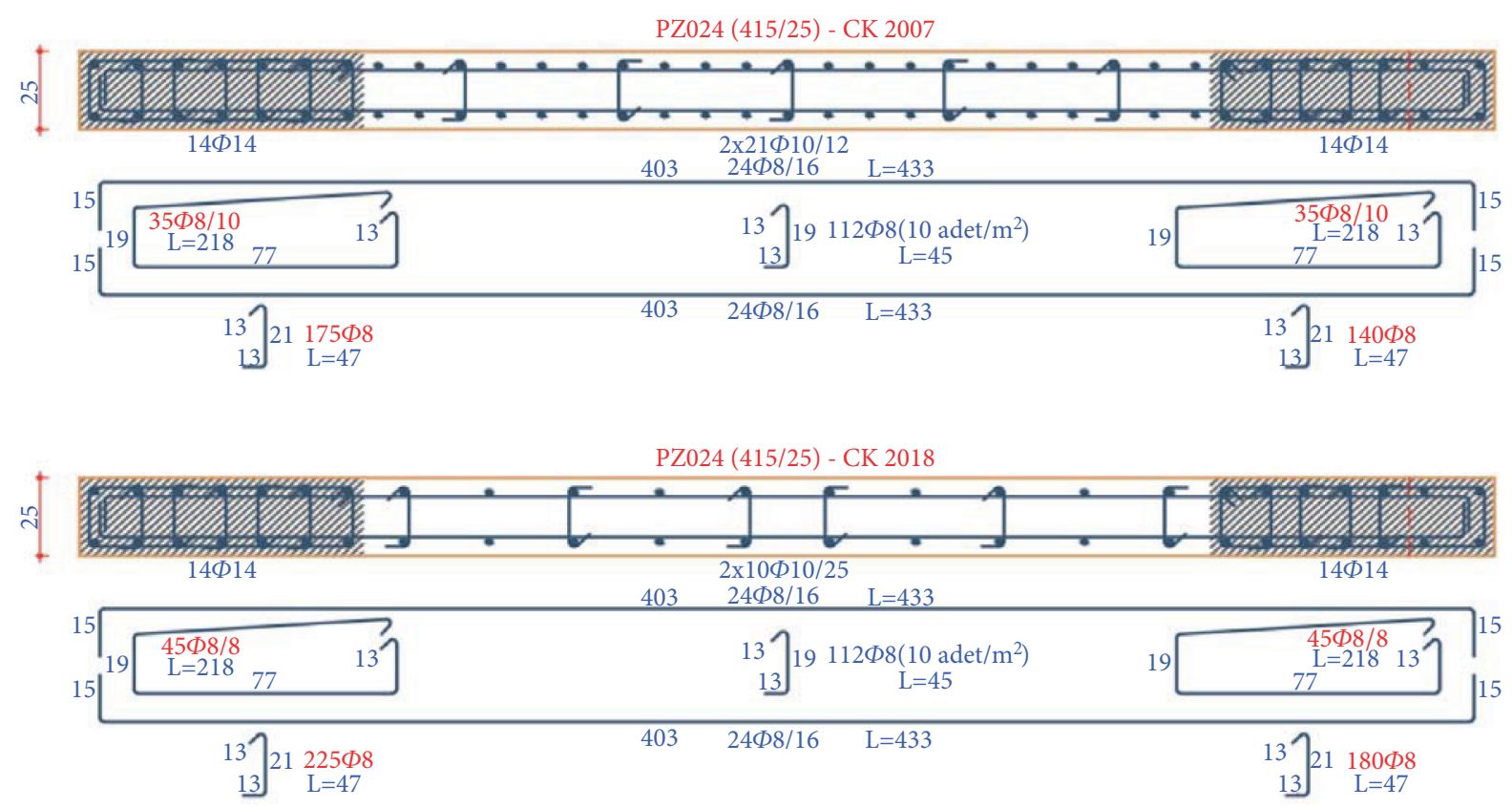

FIGURE 7: Randomly selected P024 shear wall ground floor reinforcement plan for 15-storey CK-type building.

different regulations, it can be seen that although the 2018 earthquake regulation showed no difference in terms of number and gaps for other reinforcements, the numbers of the stirrup and tie spacer significantly increases in columns, and this had direct effects on flexibility and period results. The number of stirrups in the BK building increased from 190 to 242 for the P026 shear wall, and the number of tie spacers increased from 2352 to 2768. Similarly, the number of stirrups in the CK building increased from 190 to 242 for the P024 shear wall, and the number of tie spacers increased from 1063 to 1505 . This increased the strength of the shear wall and decreased the number of required longitudinal reinforcement from 410 to 372. It is clear that the reason for all that are the terms introduced by the new regulation.
When two tables were investigated together, it was seen that the number of thin reinforcements increased both for regular BK-type buildings (Table 11) and relatively irregular CK-type buildings (Table 12). There are certain rules to change the number of thin reinforcements after the 2018 earthquake regulation. For example, a special earthquake stirrup concept emerged, and 135degrees curved hooks at both ends became mandatory. Additionally, it was stated that from the last point of the tangent at the three straight length curves of these hooks, ribbed rods could not be smaller than $\varnothing 6$ and $80 \mathrm{~mm}$. It was stated that special earthquake stirrup length should grip the reinforcement from the outside, and the hooks should be closed around the same-length reinforcement. The diameter and spacing of these tie spacers must be the 
TABLE 11: Total reinforcement quantities of P026 shear wall along with all floors on 15-storey BK-type building.

\begin{tabular}{|c|c|c|c|c|}
\hline \multicolumn{5}{|c|}{ P024 (25/620) - (BK - 2007) } \\
\hline \multicolumn{2}{|c|}{ Number Diamerter } & \multirow{2}{*}{$\frac{\text { Length }}{375}$} & \multirow{2}{*}{ Type } & \multirow{2}{*}{$\begin{array}{c}\text { Weight } \\
2854.88\end{array}$} \\
\hline 630 & 14 & & & \\
\hline 42 & 14 & 313 & $\Gamma$ & 158.86 \\
\hline \multirow[t]{2}{*}{42} & 14 & 250 & $\Gamma$ & 126.88 \\
\hline & & & & $3140.62 \mathrm{Kg}$ \\
\hline 570 & 10 & 355 & - & 1247.56 \\
\hline 40 & 10 & 313 & $\Gamma$ & 77.19 \\
\hline \multirow[t]{2}{*}{30} & 10 & 230 & $\Gamma$ & 42.54 \\
\hline & & & & $1367.30 \mathrm{Kg}$ \\
\hline 648 & 8 & 638 & $\Gamma$ & 1631.31 \\
\hline 190 & 8 & 300 & $\square$ & 224.91 \\
\hline 416 & 8 & 176 & $\square$ & 288.90 \\
\hline 2352 & 8 & 47 & & 436.19 \\
\hline \multirow[t]{2}{*}{1169} & 8 & 45 & \ulcorner & 207.57 \\
\hline & & & & $2788.88 \mathrm{Kg}$ \\
\hline \multicolumn{3}{|c|}{ Total Reinforcements (8-12) } & \multicolumn{2}{|c|}{ Total Reinforcements (14-32) } \\
\hline \multicolumn{3}{|c|}{$4156.17 \mathrm{Kg}$} & \multicolumn{2}{|c|}{$3140.62 \mathrm{Kg}$} \\
\hline
\end{tabular}

\begin{tabular}{|c|c|c|c|c|}
\hline \multicolumn{5}{|c|}{ P026 (25/620) - (BK - 2018) } \\
\hline Number & Diamerter & Length & Type & Weight \\
\hline 630 & 14 & 375 & — & 2854.88 \\
\hline 42 & 14 & 313 & $\Gamma$ & 158.86 \\
\hline \multirow[t]{2}{*}{42} & 14 & 250 & $\Gamma$ & 126.88 \\
\hline & & & & $3140.62 \mathrm{Kg}$ \\
\hline 570 & 10 & 355 & - & 1247.56 \\
\hline 40 & 10 & 313 & $\Gamma$ & 77.19 \\
\hline \multirow[t]{2}{*}{30} & 10 & 230 & $\Gamma$ & 42.54 \\
\hline & & & & $1367.30 \mathrm{Kg}$ \\
\hline 648 & 8 & 638 & $\Gamma$ & 1631.31 \\
\hline 242 & 8 & 300 & $\square$ & 286.47 \\
\hline 416 & 8 & 176 & $\square$ & 288.90 \\
\hline 2768 & 8 & 47 & & 513.34 \\
\hline \multirow[t]{2}{*}{1169} & 8 & 45 & & 207.57 \\
\hline & & & & $2927.58 \mathrm{Kg}$ \\
\hline \multicolumn{3}{|c|}{ Total Reinforcements (8-12) } & \multicolumn{2}{|c|}{ Total Reinforcements (14-32) } \\
\hline \multicolumn{3}{|c|}{$4294.88 \mathrm{Kg}$} & \multicolumn{2}{|c|}{$3140.62 \mathrm{Kg}$} \\
\hline
\end{tabular}

TABle 12: Total reinforcement quantities of P024 shear wall along with all floors on 15-storey CK-type building.

\begin{tabular}{|c|c|c|c|c|}
\hline \multicolumn{5}{|c|}{ P024 (415/25) - CK 2007} \\
\hline Number & Diamerter & Length & Type & Weight \\
\hline 408 & 14 & 375 & & 1848.87 \\
\hline 27 & 14 & 313 & $\Gamma$ & 102.12 \\
\hline \multirow[t]{2}{*}{28} & 14 & 250 & $\Gamma$ & 84.59 \\
\hline & & & & $2035.58 \mathrm{Kg}$ \\
\hline 410 & 10 & 355 & $\longrightarrow$ & 897.37 \\
\hline 26 & 10 & 313 & $\Gamma$ & 50.17 \\
\hline \multirow[t]{2}{*}{42} & 10 & 230 & $\Gamma$ & 59.56 \\
\hline & & & & $1007.10 \mathrm{Kg}$ \\
\hline 648 & 8 & 433 & $\Gamma$ & 1107.14 \\
\hline 190 & 8 & 218 & $\square$ & 163.44 \\
\hline 416 & 8 & 136 & $\bar{\square}$ & 223.24 \\
\hline 1063 & 8 & 47 & & 197.14 \\
\hline \multirow[t]{2}{*}{782} & 8 & 45 & & 138.85 \\
\hline & & & & $1829.81 \mathrm{Kg}$ \\
\hline \multicolumn{3}{|c|}{ Total Reinforcements (8-12) } & \multicolumn{2}{|c|}{ Total Reinforcements (14-32) } \\
\hline \multicolumn{3}{|c|}{$2836.91 \mathrm{Kg}$} & \multicolumn{2}{|c|}{$2035.58 \mathrm{Kg}$} \\
\hline
\end{tabular}

same as the diameter and spacing of the stirrups. There was a condition for these tie spacers to have longitudinal reinforcement and external stirrup wrapping to both ends. In terms of overlapping length, the overlapping extensions of the reinforcement on the column length should be at the middle one-third region of the column-free height. In terms of twist region length in the regulation for an increased number of reinforcements can be explained by not being smaller than.

(i) $1 / 6$ of column-free height

(ii) 1.5 times of column largest cross section length

(iii) $500 \mathrm{~mm}$

The twist region for the console columns should be created from the bottom tip of the column, the length must be smaller than two times the size of large column dimensions, and these reinforcements should continue inside the foundation at a height without being smaller than the minimum column size were expressed in 2018 earthquake regulation.

\begin{tabular}{|c|c|c|c|c|}
\hline \multicolumn{5}{|c|}{ P024 (415/25) - CK 2018} \\
\hline Number & Diamerter & Length & Type & Weight \\
\hline 408 & 14 & 375 & & 1848.87 \\
\hline 27 & 14 & 313 & $\Gamma$ & 102.12 \\
\hline \multirow[t]{2}{*}{28} & 14 & 250 & $\Gamma$ & 84.59 \\
\hline & & & & $2035.58 \mathrm{Kg}$ \\
\hline 372 & 10 & 355 & 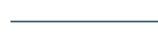 & 814.20 \\
\hline 26 & 10 & 313 & $\Gamma$ & 50.17 \\
\hline \multirow[t]{2}{*}{20} & 10 & 230 & $\Gamma$ & 28.36 \\
\hline & & & & $892.73 \mathrm{Kg}$ \\
\hline 648 & 8 & 433 & $\Gamma$ & 1107.14 \\
\hline 242 & 8 & 218 & $\square$ & 208.17 \\
\hline 416 & 8 & 136 & $\square$ & 223.24 \\
\hline 1505 & 8 & 47 & & 279.11 \\
\hline \multirow[t]{2}{*}{756} & 8 & 45 & \ulcorner & 134.24 \\
\hline & & & & $1973.23 \mathrm{Kg}$ \\
\hline \multicolumn{3}{|c|}{ Total Reinforcements (8-12) } & \multicolumn{2}{|c|}{ Total Reinforcements (14-32) } \\
\hline \multicolumn{3}{|c|}{$2865.97 \mathrm{Kg}$} & \multicolumn{2}{|c|}{$2035.58 \mathrm{Kg}$} \\
\hline
\end{tabular}

When the required reinforcement ratio (Table 13) and axial load tables (Table 14) of randomly selected P026 and P024 shear walls for floors were investigated, it was seen that the axial load ratio in 2007 earthquake regulation was higher for both shear walls compared to 2018 regulation and the necessary reinforcement area was higher. Since similar data were obtained for both structure type and each floor, it is expected that the number of reinforcements of the building constructed for the 2018 regulation would be lower.

3.2. Findings for Cost. The analyzed buildings were evaluated in terms of cost under two main titles. These differences emerged first due to regulation changes and second due to differences caused by increased floors.

3.2.1. Cost Difference due to Regulation Change. Static designs of two different structures (BK and CK) were created for different floors, and quantities were calculated for the two different regulations. Although the regulations had 
TABLE 13: Required reinforcement ratio for floors of P026-P024 shear wall for 15-storey BK and CK buildings $\left(\mathrm{cm}^{2} / \mathrm{cm}^{2}\right.$.

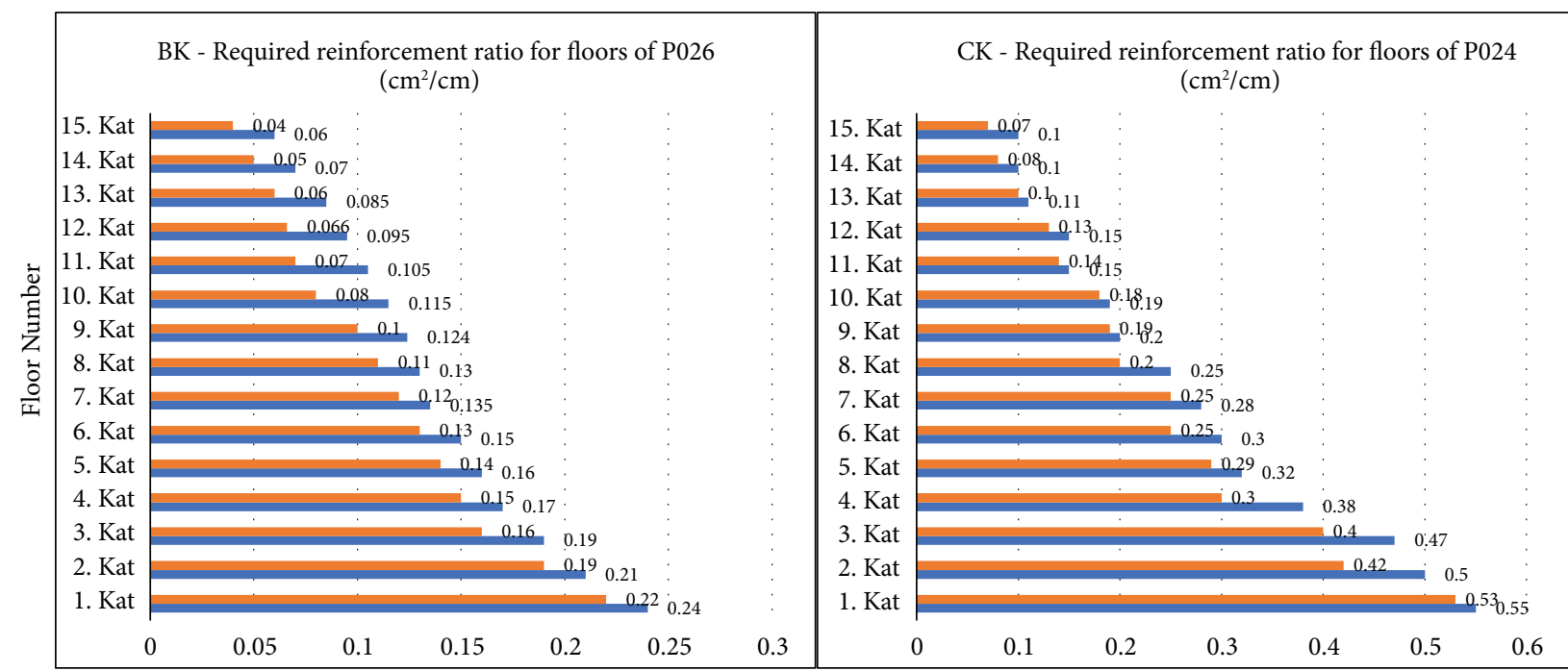

Required Reinforcement Ratio $\left(\mathrm{cm}^{2} / \mathrm{cm}\right)$

$\begin{array}{rr}2018 & \square 2018 \\ 2007 & \square\end{array}$

TABLe 14: Axial load for floors of P026-P024 shear wall for 15-storey BK and CK buildings (ton/cm).

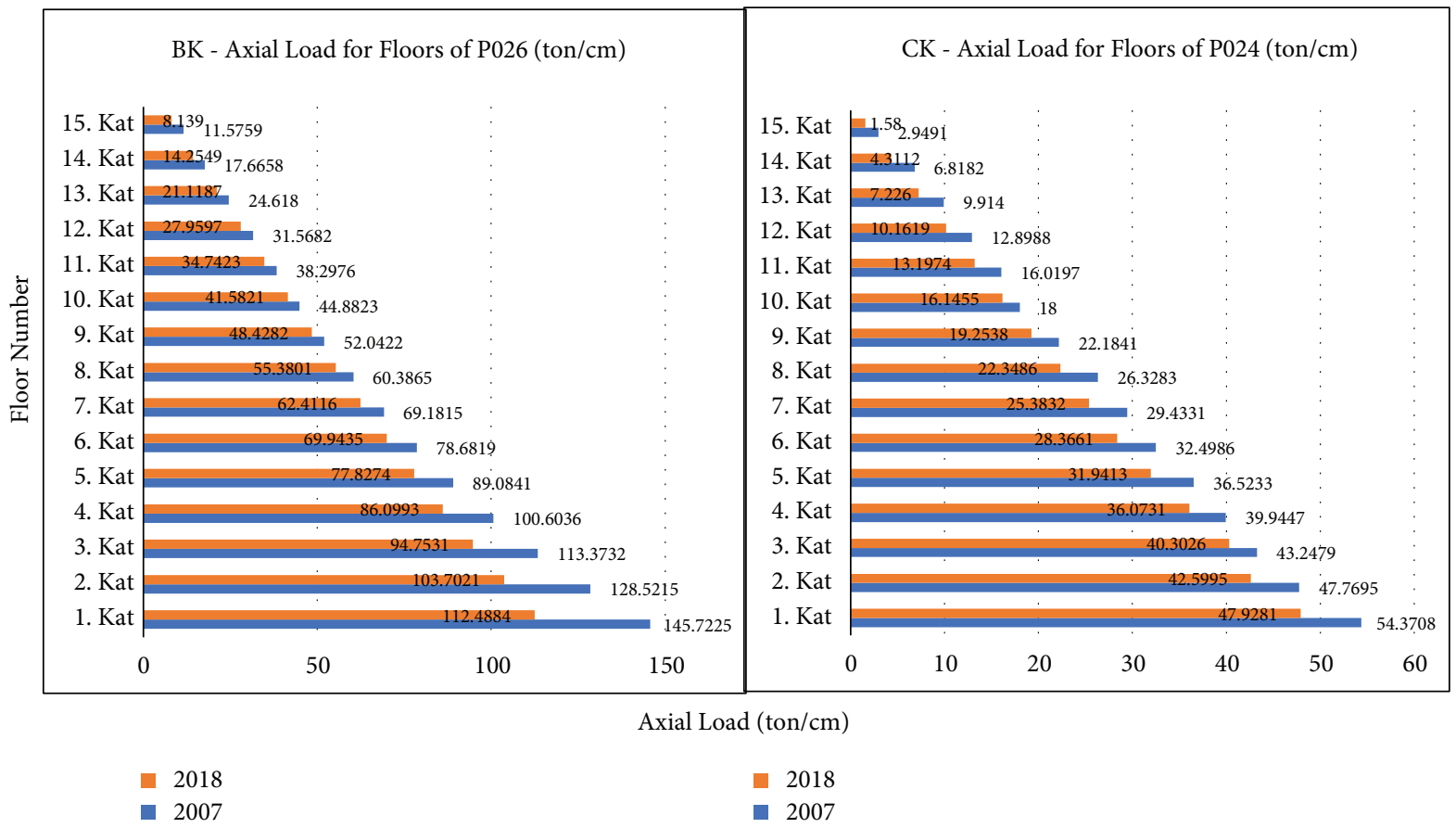

differences, the amount of concrete and formwork did not change, and the reinforcements caused the difference. S420type ribbed reinforced concrete steel was selected for the design.

If BK block quantities (Table 15) were considered, a slight increase was observed for both thin reinforcement and thick reinforcement quantities in 5-storey examples different from the others. For 10-storey and 15-storey examples, there was a $4-5 \%$ decrease in thin reinforcements and around $3-4 \%$ increase in thick reinforcements. There was a $0.31 \%$ increase in the 5 -storey structure, a $1.72 \%$ decrease in 10 -storey structure, and a $1.05 \%$ decrease in the 15-storey structure.

If CK block quantities (Table 16) were considered, a slight increase was observed for both thin reinforcement and thick reinforcement quantities in 5-storey examples 
TABLE 15: BK structure quantities.

\begin{tabular}{|c|c|c|c|c|c|c|}
\hline & \multicolumn{2}{|c|}{5 floors } & \multicolumn{2}{|c|}{10 floors } & \multicolumn{2}{|c|}{15 floors } \\
\hline & 2007 & 2018 & 2007 & 2018 & 2007 & 2018 \\
\hline BS30 concrete, $\mathrm{m}^{3}$ & 1987.2 & 1987.2 & 2981.8 & 2981.8 & 3977.5 & 3977.5 \\
\hline Concrete formwork, $-\mathrm{m}^{2}$ & 10413.5 & 10413.5 & 18831.0 & 18831.0 & 27335.7 & 27335.7 \\
\hline Base slab & 120.7 & 120.7 & 120.7 & 120.7 & 120.7 & 120.7 \\
\hline Shear wall & 1086.0 & 1086.0 & 1071.8 & 1071.8 & 1071.8 & 1071.8 \\
\hline Flooring & 577.2 & 577.2 & 577.2 & 577.2 & 577.2 & 577.2 \\
\hline Beam & 52.2 & 52.2 & 51.9 & 51.9 & 51.9 & 51.9 \\
\hline S420C reinforcement (thin), kg & 66252.4 & 66363.9 & 119065.6 & 114285.7 & 170829.6 & 162764.8 \\
\hline S420C reinforcement (thick), kg & 82650.2 & 83000.0 & 97536.9 & 98654.0 & 114719.3 & 119803.8 \\
\hline S420C reinforcement (total), kg & 148902.6 & 149363.9 & 216602.5 & 212939.7 & 285548.8 & 282568.6 \\
\hline Total reinforcement difference, $\%$ & & $+0.31 \%$ & & $-1.72 \%$ & & $-1.05 \%$ \\
\hline
\end{tabular}

TABLE 16: CK structure quantities.

\begin{tabular}{|c|c|c|c|c|c|c|}
\hline & \multicolumn{2}{|c|}{5 floors } & \multicolumn{2}{|c|}{10 floors } & \multicolumn{2}{|c|}{15 floors } \\
\hline & 2007 & 2018 & 2007 & 2018 & 2007 & 2018 \\
\hline BS30 concrete, $\mathrm{m}^{3}$ & 2685.5 & 2685.538 & 4078.8 & 4078.8 & 5468.1 & 5468.1 \\
\hline Concrete formwork, $\mathrm{m}^{2}$ & 13031.2 & 13031.24 & 23771.9 & 23771.9 & 34512.6 & 34512.6 \\
\hline Base slab & 142.4 & 142.4 & 142.4 & 142.4 & 142.4 & 142.4 \\
\hline Shear wall & 1347.6 & 1347.6 & 1347.6 & 1347.6 & 1347.6 & 1347.6 \\
\hline Flooring & 727.5 & 727.5 & 727.5 & 727.5 & 727.5 & 727.5 \\
\hline Beam & 73.1 & 73.1 & 73.1 & 73.1 & 73.1 & 73.1 \\
\hline S420C reinforcement (thin), kg & 88942.5 & 89128.6 & 162696.7 & 158846.7 & 233322.5 & 227751.9 \\
\hline S420C reinforcement (thick), kg & 93645.1 & 93588.3 & 124044.7 & 121041.5 & 152553.7 & 143601.0 \\
\hline S420C reinforcement (total), $\mathrm{kg}$ & 182587.6 & 182716.93 & 286741.4 & 279888.2 & 385876.2 & 371352.9 \\
\hline Total reinforcement difference, $\%$ & & $+0.07 \%$ & & $-2.45 \%$ & & $-3.91 \%$ \\
\hline
\end{tabular}

different from the others. For 10-storey and 15-storey examples, there was a $1.5-2.5 \%$ decrease in thin reinforcements and around a 3-4\% decrease in thick reinforcements. There was a $0.07 \%$ increase in the 5 -storey structure, $2.45 \%$ decrease in the 10-storey structure, and $3.91 \%$ decrease in the 15-storey structure. The reason for thick reinforcement increases in BK-type block, and the decrease here was designed with smaller diameter reinforcement is more advantageous depending on the received force for some components. The minimum required reinforcement must be met at the most optimum way according to the regulation. According to this program-based optimization, the evolution of the total of thin and thick reinforcements must be taken into account. As expected, the increased number of floors for shear load on the floors show that the new regulation considered this and the cost-saving in this situation.

3.2.2. Impact of Number of Floors on Cost. Two factors make the tunnel formwork method advantageous: the first is the low labor and general expenses due to fast construction. The second advantage is that once the formwork is prepared, it can be used with high numbers. This study investigates how the number of floors impacts the cost.

This study considered $2 \%$ material repair and reconstruction for each dismounting and mounting process once the tunnel formwork materials were prepared. This ratio was obtained based on market research, and the ratio might change depending on the usage and workers.
In a tunnel formwork system, one floor per day is generally aimed. Therefore, the limiting factor for this study was identified as one-floor formwork manufacturing per day. The required labor to pour one floor of concrete on one day (4 flats) was determined after mutual meetings with active tunnel formwork sub-contractor firms on the market rather than the Ministry of Environment and Urban Affairs. In the Ministry of Environment and Urban Affairs analysis, the prices proportionally increased the total cost as the related amount increased. Thus, the calculated cost for 2-floor tunnel formwork construction to the calculated cost for 2-floor tunnel formwork construction would be 20/ 2 , which is 10 . Yet, this is not the real-life scenario. After the tunnel formwork is manufactured, it can be used approximately 500 times with small repair and proper use. Similar properties for building schemes and their environmental impacts and achieve the visualization of life cycle assessment (LCA) results in communication and design guidance. $[17,18]$.

Daily one floor concrete laying target can be met with the 50-people team and 13 hours of work for BK-type structure and with 66-people team and 13-hour work for CK-type structure. The number of the team was determined as a result of mutual interviews with tunnel formwork sub-contractors.

The cost profitability here comes from using the tunnel formwork multiple times. Labor is proportional with time, and equipment is proportional with $\mathrm{m}^{2}$. Therefore, the size of the work is directly proportional to the cost of these factors and inversely proportional to the material. 
TABLE 17: BK block cost components.

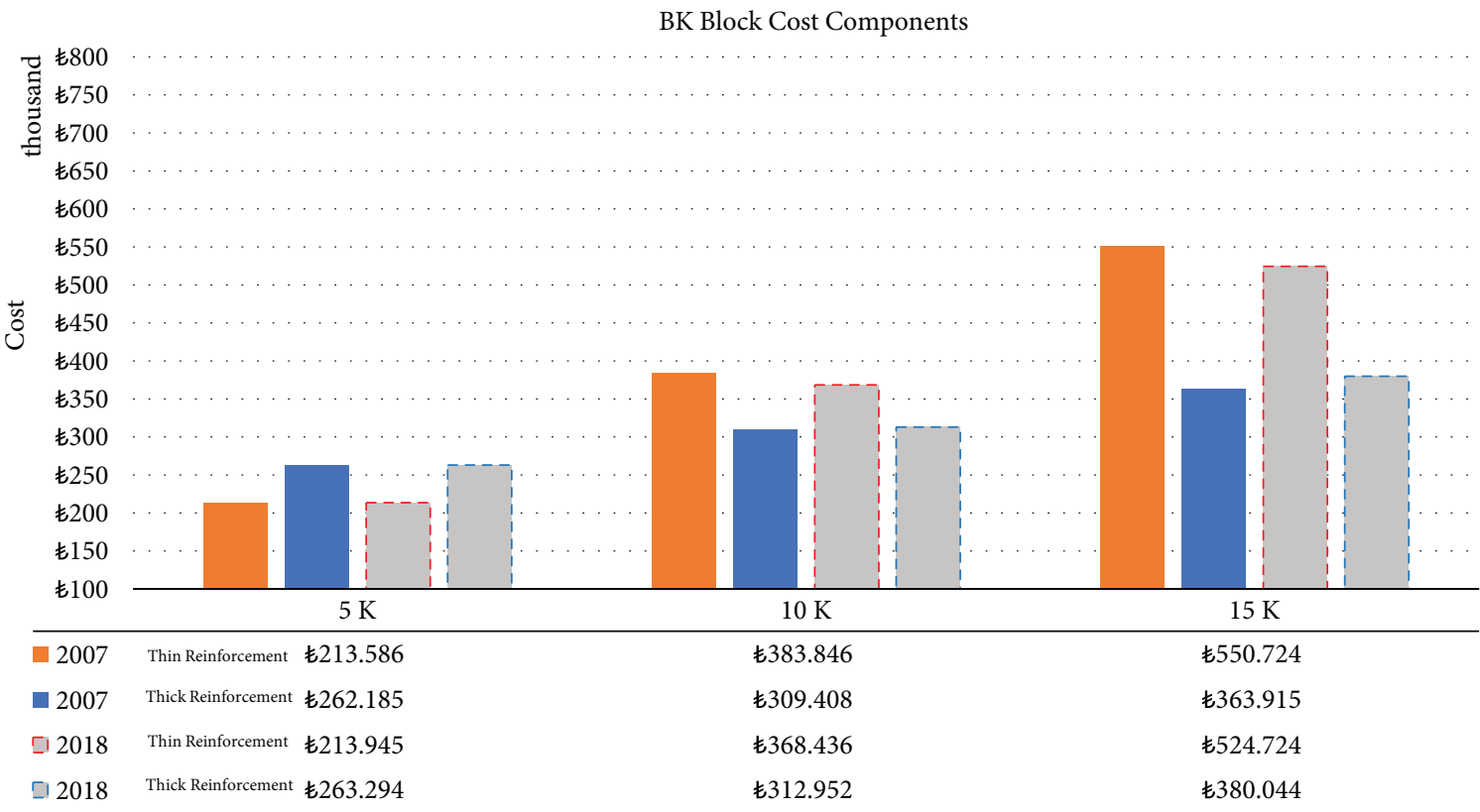

Floor

TABLE 18: BK block costs.

\begin{tabular}{|c|c|c|c|c|c|c|c|c|c|c|}
\hline & $\begin{array}{c}\text { Floor } \\
(\mathrm{K})\end{array}$ & Concrete & $\begin{array}{c}\text { Difference } \\
(\%)\end{array}$ & $\begin{array}{l}\text { Thin } \\
\text { reinforcement }\end{array}$ & $\begin{array}{c}\text { Difference } \\
(\%)\end{array}$ & $\begin{array}{l}\text { Thick } \\
\text { reinforcement }\end{array}$ & $\begin{array}{c}\text { Difference } \\
(\%)\end{array}$ & Molding & $\begin{array}{c}\text { Difference } \\
(\%)\end{array}$ & Total \\
\hline \multirow{3}{*}{ TSC-2007 } & 5 & も349.913 & & Ł213.586 & & Ł262.185 & & も156.538 & & も982.221 \\
\hline & 10 & も525.047 & 50 & も383.846 & 80 & も309.408 & 18 & も282.634 & 81 & も1.500.936 \\
\hline & 15 & も700.384 & 33 & も550.724 & 43 & も363.915 & 18 & も409.446 & 45 & $€ 2.024 .468$ \\
\hline \multirow{3}{*}{ TSCB-2018 } & 5 & も349.913 & & €213.945 & & $€ 263.294$ & & も156.538 & & Ł983.690 \\
\hline & 10 & も525.047 & 50 & も368.436 & 72 & も312.952 & 19 & $€ 282.634$ & 81 & も1.489.070 \\
\hline & 15 & も700.384 & 33 & Ł524.724 & 42 & も380.044 & 21 & も409.446 & 45 & $€ 2.014 .598$ \\
\hline
\end{tabular}

TABLE 19: CK block cost components.

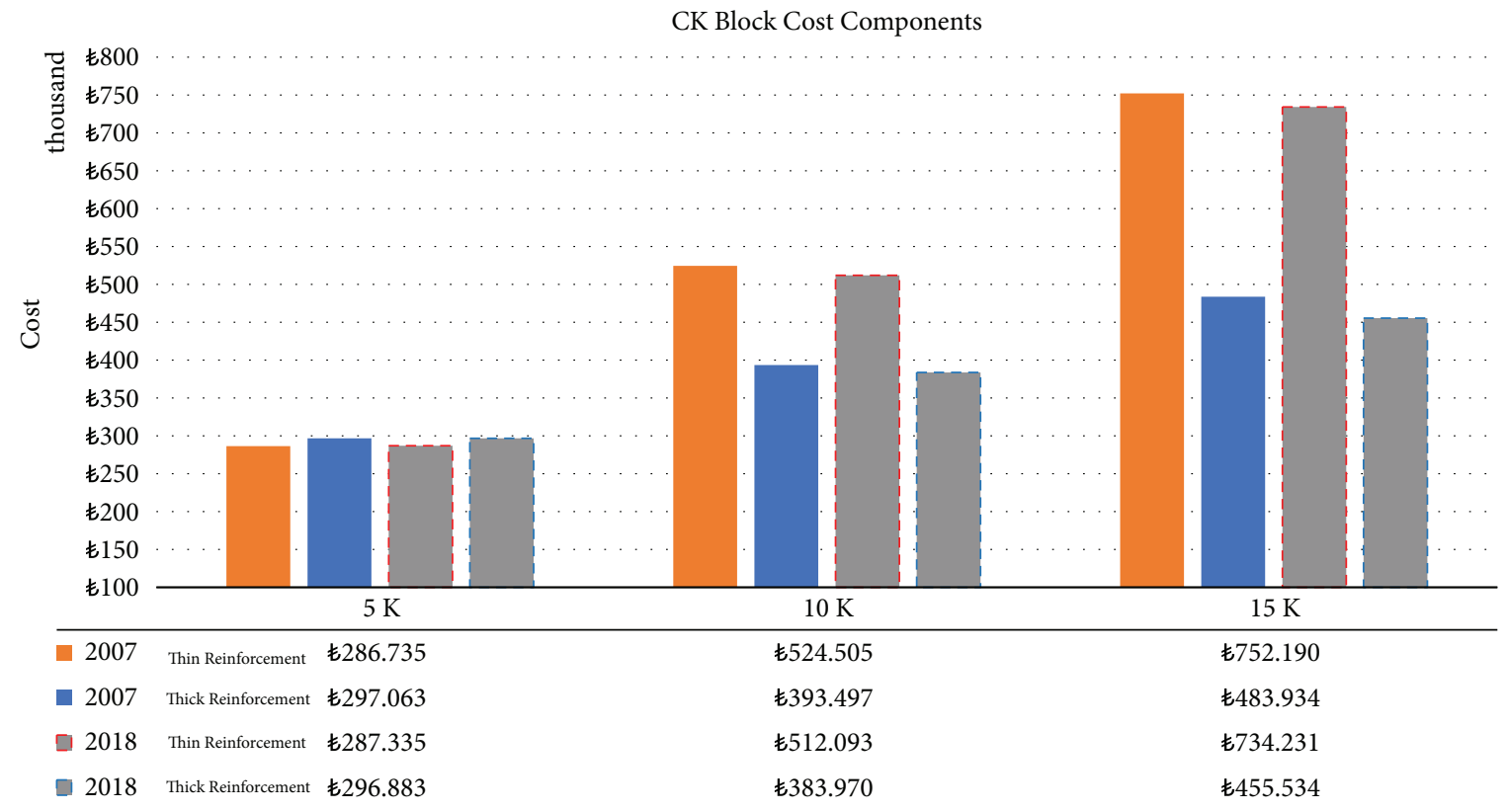


TABLE 20: CK block costs.

\begin{tabular}{|c|c|c|c|c|c|c|c|c|c|c|}
\hline & $\begin{array}{c}\text { Floor } \\
(\mathrm{K})\end{array}$ & Concrete & $\begin{array}{c}\text { Difference } \\
(\%)\end{array}$ & $\begin{array}{l}\text { Thin } \\
\text { reinforcement }\end{array}$ & $\begin{array}{c}\text { Difference } \\
(\%)\end{array}$ & $\begin{array}{c}\text { Thick } \\
\text { reinforcement }\end{array}$ & $\begin{array}{c}\text { Difference } \\
(\%)\end{array}$ & Molding & $\begin{array}{c}\text { Difference } \\
(\%)\end{array}$ & Total \\
\hline \multirow{3}{*}{ TSC-2007 } & 5 & も472,882 & & Ł286,735 & & $£ 297,063$ & & も195,750 & & €1,252,430 \\
\hline & 10 & も718,218 & 52 & Ł524,505 & 83 & €393,497 & 32 & €355,465 & 82 & Ł1,991,685 \\
\hline & 15 & も962,856 & 34 & も752,190 & 43 & も483,934 & 23 & も515,180 & 45 & $€ 2,714,159$ \\
\hline \multirow{3}{*}{ TSCB-2018 } & 5 & も472,882 & & $€ 287,335$ & & $€ 296,883$ & & も195,750 & & $€ 1,252,850$ \\
\hline & 10 & も718,218 & 52 & Ł512,093 & 78 & $€ 383,970$ & 29 & $€ 355,465$ & 82 & Ł1,969,746 \\
\hline & 15 & Ł962,856 & 34 & も734,231 & 43 & $€ 455,534$ & 19 & €515,180 & 45 & $€ 2,667,800$ \\
\hline
\end{tabular}

TABLE 21: BK structure $\mathrm{m}^{2}$ costs.

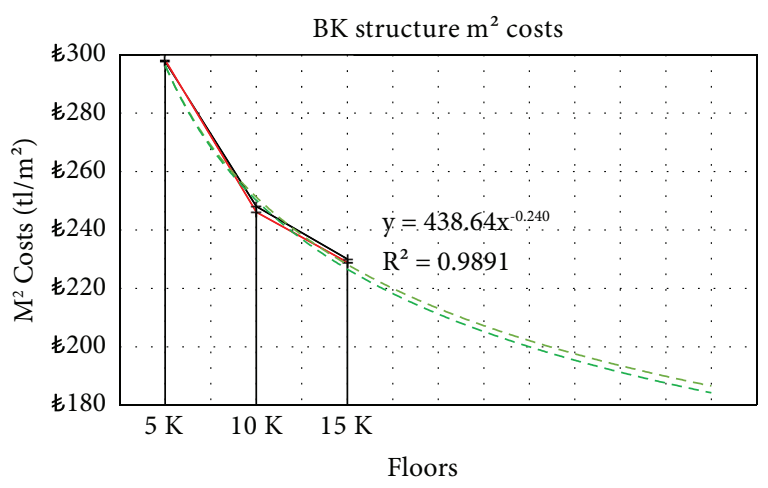

- BK 2007

+ BK 2018

TABLE 22: CK structure $\mathrm{m}^{2}$ costs.

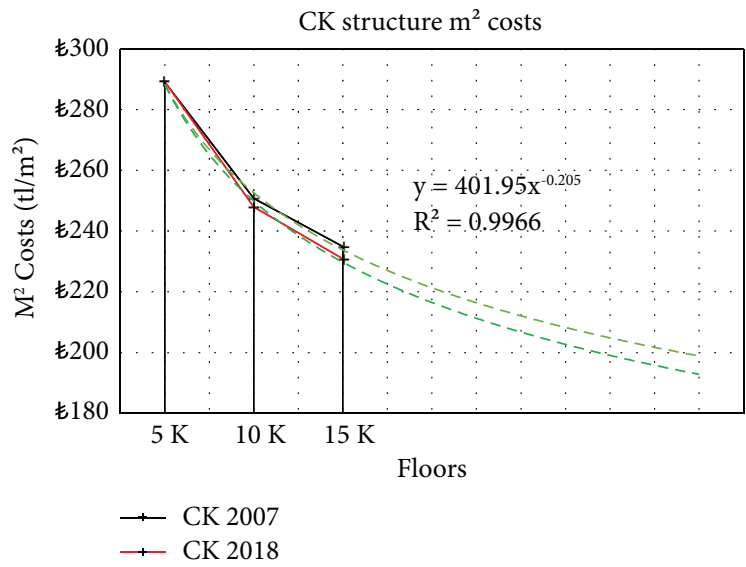

When all cost components were considered, the total cost for BK (Tables 17 and 18) and CK-type structures (Tables 19 and 20) were calculated, prices per $\mathrm{m}^{2}$ were obtained, and the values were presented in the table. Since tunnel formwork was reused on other floors as the number of floors increased, cost per $\mathrm{m}^{2}$ decreased, and a curve on the table was obtained. The possible values of this curve obtained with "curve fitting" analysis were added to the table as “Exponential 2007" and "Exponential 2018." The purpose here was to guide the future to calculate the $\mathrm{m}^{2}$ cost per number of floors. In the calculations made with the obtained formula, it is seen that the cost per unit $\mathrm{m}^{2}$ decreases as the number of floors increases. Since the formula is logarithmic, as the number of floors increases, the profit per $\mathrm{m}^{2}$ decreases gradually and decreases considerably after a point, this situation can be seen quite clearly in the table of unit costs per $\mathrm{m}^{2}$ of BK (Table 21) and CK (Table 22) type buildings obtained with the help of empirical formula (Table 23). 
TABLE 23: Structure $\mathrm{m}^{2}$ costs.

\begin{tabular}{|c|c|c|c|c|}
\hline \multirow{2}{*}{ Floor number } & \multicolumn{4}{|c|}{$\mathrm{m}^{2} \operatorname{cost}(\mathrm{TL})$} \\
\hline & BK type building & Difference & CK type building & Difference \\
\hline 1 & 438.64 & & 401.95 & \\
\hline 5 & 296.18 & 142.46 & 288.06 & 113.89 \\
\hline 10 & 250.10 & 46.09 & 249.56 & 38.50 \\
\hline 15 & 226.54 & 23.56 & 229.47 & 20.09 \\
\hline 20 & 211.18 & 15.36 & 216.20 & 13.27 \\
\hline 25 & 199.99 & 11.19 & 206.44 & 9.76 \\
\hline 30 & 191.29 & 8.70 & 198.80 & 7.65 \\
\hline 35 & 184.23 & 7.06 & 192.55 & 6.24 \\
\hline 40 & 178.32 & 5.91 & 187.30 & 5.25 \\
\hline 45 & 173.27 & 5.05 & 182.79 & 4.51 \\
\hline 50 & 168.87 & 4.40 & 178.85 & 3.94 \\
\hline$\ldots$ & $\ldots$ & $\ldots$ & $\ldots$ & $\ldots$ \\
\hline$\ldots$ & $\ldots$ & $\ldots$ & $\ldots$ & $\ldots$ \\
\hline 98 & 143.30 & 0.36 & 155.59 & 0.33 \\
\hline 99 & 142.95 & 0.35 & 155.27 & 0.33 \\
\hline 100 & 142.60 & 0.35 & 154.94 & 0.32 \\
\hline
\end{tabular}

\section{Results}

When TSCB-2018 and TSC-2007 were compared in general, some of the parameters in TSC-2007 were unnecessary safety elements, and the more detailed work and tables of TSCB2018 provided more optimized results.

4.1. Results for Strength. The changes in structure height with new defined maps and new calculating parameters provide more realistic results in the new regulation. The following changes were obtained with the new earthquake regulation.

(i) According to the analysis, the dominant natural vibration period of the structure increased $7.3 \%$ for the 5 -storey structure with a regular plan, $7.0 \%$ for the 10 storey structure, and $6.1 \%$ for 15 -storey structure. In more irregular structures, there was a $4.8 \%$ increase for 5 -storey structures, a 5,2\% increase for 10 -storey structures, and a $2.1 \%$ increase in 15 -storey structures. Therefore, in the analyses made according to TBDY2018, there was an increase in the natural vibration period values of the structure in both building types compared to TDY-2007. This period increase occurs because effective section stiffness has to be taken into account according to the calculation principles in the new regulation.

(ii) The analysis for shear force on the floors showed a $3.9 \%$ increase for 5-storey regular structures, $38.4 \%$ for 10 -storey buildings, and $43.3 \%$ for 15 -storey structures for the new regulation compared to the old regulation. More irregular structures increased by $7.3 \%$ for 5 storey and decreased by $38.9 \%$ for 10 storey structures and $43.6 \%$ for 15 -storey structures.

(iii) Floor displacement increased $71.4 \%$ for 5-storey regular structures, increased $11.25 \%$ for 10 -storey structures, and decreased $25.3 \%$ for 15 -storey structures. More irregular CK structures increased by
$76.9 \%$ for 5 storey, decreased by $2.9 \%$ for 10 -storey structures, and $16.1 \%$ for 15-storey structures.

(iv) When decreased floor displacement, which represents the displacement difference between two consecutive floors, was considered, this value increased $75.6 \%$ for 5 -storey regular structure, decreased $6.1 \%$ for 10 -storey structure, and decreased $19.7 \%$ for 15 -strorey structure. More irregular CK structures increased by $82.8 \%$ for 5 -storey and $2.1 \%$ for 10 -storey structures and decreased by $10.3 \%$ for 15-storey structures.

(v) When the samples with different floors were investigated both from regular and irregular structure types, it was seen that the relative floor displacement values of the structure constructed for 2007 earthquake regulation increased depending on the building height, and the structure behaved as a whole when constructed for 2018 earthquake regulation. The displacement between floors provided relatively more stable results for 2018 earthquake regulation, and it was seen that there was a similarity between neighboring floors.

(vi) While similar results were obtained in both types of structures in the linear and non-linear thrust analysis made with the 2007 regulation, it was observed that the non-linear analysis made relatively more displacement in the analyses made with the 2018 regulation, and this regulation gave more appropriate results to the natural behaviour of the material.

(vii) When the required reinforcement ratio and axial load tables of randomly selected P026 and P024 shear walls for floors were investigated, the axial load amount of shear walls of the building constructed for 2018 regulation was lower than the building constructed for 2007 regulation and in line with this result, the required reinforcement area for the 2018 building was lower. Since similar data were 
obtained for both structure type and each floor, it was found that the number of reinforcements of the building constructed for the 2018 regulation would be lower.

When the effects were considered for strength, the dominant building period, ground period, and ground motion were the most effective factors. These differences occurred because all these parameters were reworked in TSCB-2018 with more detail. The reason for the S-shape of the building was that the dominant building period increased as the structure height increased, and the building was able to behave more flexibly as a whole. The reason for not seeing this clearly in TSC-2007 was choosing a more rigid design for the selected location and building periods, thus decreasing the structure's motion ability as a whole.

4.2. Results for Cost. According to the new earthquake regulation and 2007 earthquake regulation analysis, total cost differences were obtained from reinforcement differences.

(i) For BK structure which is more regular in TSCB2018analysis than TSC-2007 analysis, $0.31 \%$ increase was obtained for the total cost for 5-storey buildings, $1.72 \%$ decrease for 10 -storey structures, and $1.05 \%$ decrease in 15 -storey structures. For less regular CK structures, $0.07 \%$ increase was obtained for the total cost for 5-storey buildings, $2.45 \%$ decrease for 10 -storey structures, and $3.91 \%$ decrease in 15-storey structures. If these results are interpreted, there was a $1 \%$ additional cost for lowrise structures with TSCB-2018 depending on the number of floors and floor plan and a small saving as the number of floors increased.

(ii) When coefficient-based cost changes were investigated, the total cost of 10-storey building for a regular BK-type structure was 51\% higher than the 5 -storey building, and the total cost of the 15-storey building was $105 \%$ higher than the 5-storey building based on the analysis for TSCB-2018. The total cost of 10-storey building for a more irregular BK-type structure was $57 \%$ higher than the 5-storey building, and the total cost of the 15-storey building was $113 \%$ higher than the 5-storey building. According to these results, the cost of building two 5 -storey buildings is equal to the cost of one 15storey building.

(iii) In terms of building sq. $\mathrm{m}$ costs, for BK-type structure, sq. $\mathrm{m}$ costs of the 10-storey structures were $17.4 \%$ lower than 5-storey structures, and sq. $\mathrm{m}$ costs of the 15 -storey structures were $23.2 \%$ lower than the 5-storey structures. For less regular CK-type structures, sq. m costs of the 10-storey structures were $14.2 \%$ lower than 5-storey structures, and sq. m costs of the 15-storey structures were $20.1 \%$ lower than the 5-storey structures.

(iv) The "curve fitting" analysis results show that the $\mathrm{m}^{2}$ cost equation obtained for BK-type structure is as follows:

$$
y_{B K}=438,64 \cdot x^{-0,244}
$$

(v) The equation for CK-type structure is as follows:

$$
y_{C K}=401,95 \cdot x^{-0,207} \text {. }
$$

(vi) Here, $y$ represents $\mathrm{m}^{2}$ cost and $x$ represents the number of floors.

(vii) Comparative studies on tunnel formed building can be classified as contemporary structures using both life-cycle cost (LCC) and life cycle assessment (LCA) have importance with respect to holistically identifying the optimal economic and environmental solutions for sustainable designs.

\section{Data Availability}

Technical data of this work can be accessed from the institute of science of the university, as well as from the thesis archive of YOK, which is the official archive of the higher education institution in Turkey, and all data, models, or code generated or used during the study are available from the corresponding author upon request.

\section{Conflicts of Interest}

The authors declare that they have no conflicts of interest.

\section{References}

[1] J. Nasvik, "Building with tunnel forms. Concrete construction magazine," 2003, https://www.concreteconstruction.net/ projects/commercial-industrial/building-with-tunnel-forms.

[2] Z. Y. Harmankaya and M. E. Tuna, "Effects of number of storeys and concrete strength on the building cost of the multi storied buildings produced by using tunnel form in Turkey," Journal of the Faculty of Engineering and Architecture of Gazi University, vol. 26, no. 2, pp. 427-433, 2011.

[3] A. E. Amini, Tunel Formwork Systems Comparing with Wooden Formwork Systems in Terms of Time, İstanbul Aydin University, Istanbul, Turkey, 2016.

[4] M. Şenel, Experimental Study of the Seismic Behavior of Tunnel Form, Pamukkale University, Denizli, Turkey, 2002.

[5] C. Balkaya and E. Kalkan, "Nonlinear seismic response evaluation of tunnel form building structures," Computers \& Structures, vol. 81, no. 3, pp. 153-165, 2003.

[6] N. N. Bulgu, Earthquake Behaviour of Structures that Built with Tunnel Form, Istanbul Technical University, Istanbul, Turkey, 2007.

[7] IdeStatik, IdeSTATIK, IDS/NC Manual Book, Ide Construction Ltd, Istanbul, Turkey, 2006. 
[8] Ministry of Public Works and Settlement, "Regulation on buildings to be constructed in earthquake zones," 2007, https://www.resmigazete.gov.tr/eskiler/2018/03/20180318M1-2. htm.

[9] Disaster and Emergency Management Presidency, "Turkey building earthquake regulation," 2018, https://www. resmigazete.gov.tr/eskiler/2018/03/20180318M1-2.htm.

[10] H. Sezen, K. J. Elwood, A. Whittaker, K. M. Mosalam, J. W. Wallace, and J. F. Stanton, Structural Engineering Reconnaissance of the August 17, 1999 Earthquake: Kocaeli (Izmit), Turkey, University of California, Berkeley, CA, USA, 2000.

[11] G. Tunc and T. Tanfener, "Comparison of Turkish building and earthquake code in 2007 with Turkish earthquake code 2016 by examples," 2016, https://www.researchgate.net/ publication/311101553_2007_ve_2016_Turkiye_Bina_Deprem_ Yonetmeliklerinin_Orneklerle_Mukayesesi.

[12] AFAD, "Earthquake map," fhttps://www.afad.gov.tr/kurumlar/ afad.gov.tr/24212/pics/image-b592cc237f473.png?c=9064, 2021.

[13] AFAD, "Turkey earthquake hazard map," 2021, https://www. afad.gov.tr/kurumlar/afad.gov.tr/24212/pics/image-9ced40a1 b1844.png?c=3250.

[14] S. Yaman, H. Tekeli, and F. Demir, "Betonarme bpydbpe," European Journal of Science and Technology, vol. 16, pp. 194-204, 2019.

[15] B. Sahin, "Determination of building performance in earthquakes with non-linear elastic methods and comparison of the results of the methods," Master Thesis, p. 138, Yildız Technical University Institute of Science, Department of Civil Engineering, Istanbul, Turkey, 2010.

[16] H. Elci and K. Akca, "Comparison of earthquake codes (TEC 2007 and TBEC 2018) in terms of seismic performance of RC columns," International Journal of Scientific and Technological Research, vol. 4, no. 6, pp. 9-21, 2018.

[17] S. Nolan, M. Rossini, C. Knight, and A. Nanni, "New directions for reinforced concrete coastal structures," Journal of Infrastructure Preservation and Resilience, vol. 2, no. 1, pp. 1-12, 2021.

[18] A. Yang, M. Han, Q. Zeng, and Y. Sun, “Adopting building information modeling (bim) for the development of smart 18. Buildings: a review of enabling applications and challenges," Advances in Civil Engineering, vol. 2021, Article ID 8811476, 26 pages, 2021. 